Portland State University

PDXScholar

1979

\title{
A feasibility analysis of a directly sun-pumped carbon dioxide laser in space
}

Seiichi Morimoto

Portland State University

Follow this and additional works at: https://pdxscholar.library.pdx.edu/open_access_etds

Part of the Materials Science and Engineering Commons Let us know how access to this document benefits you.

\section{Recommended Citation}

Morimoto, Seiichi, "A feasibility analysis of a directly sun-pumped carbon dioxide laser in space" (1979). Dissertations and Theses. Paper 2798.

https://doi.org/10.15760/etd.2794

This Thesis is brought to you for free and open access. It has been accepted for inclusion in Dissertations and Theses by an authorized administrator of PDXScholar. Please contact us if we can make this document more accessible: pdxscholar@pdx.edu. 
AN ABSTRACT OF THE THESIS OF Seiichi Morimoto for the Master of Science in Applied Science presented May 17, 1979.

Title: A Feasibility Analysis of a Directly Sun-Pumped Carbon Dioxide Laser in Space.

APPROVED BY MEMBERS OF THE THESIS COMMITTEE:
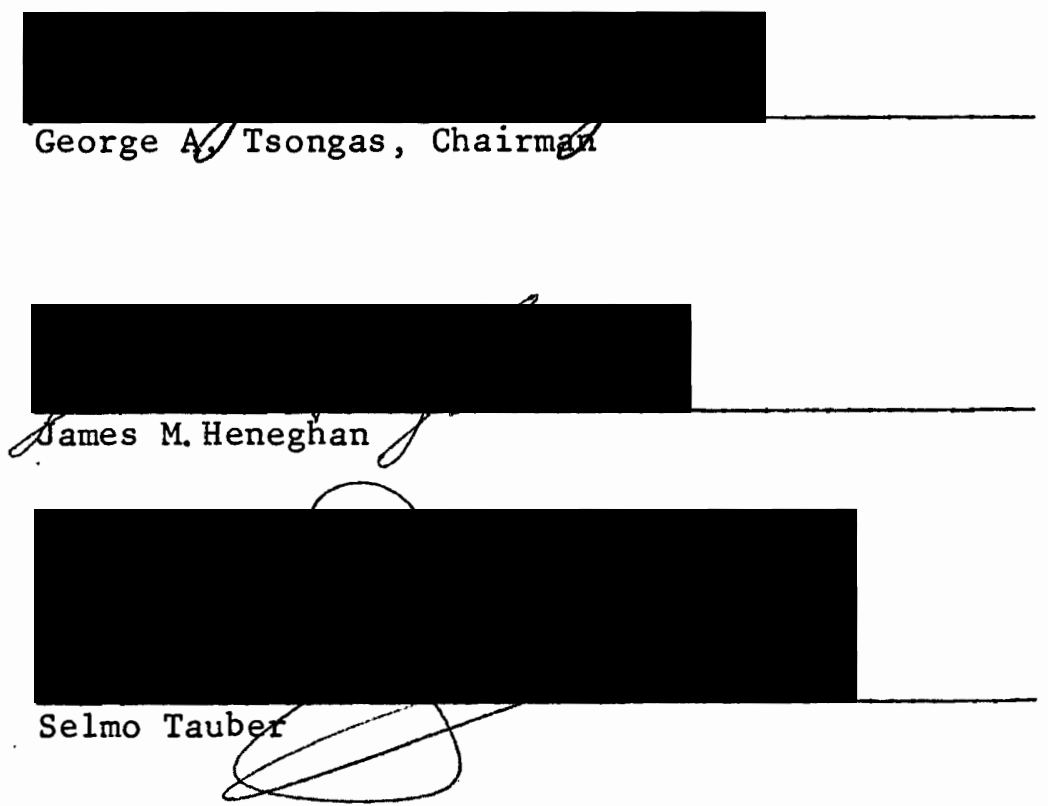

The possibility of using sunlight to pump a CW carbon dioxide laser has been analyzed. Such a laser could be of interest for such applications as space communication and power transmission. In order to optically pump $\mathrm{CO}_{2}$ using sunlight, the intense vibrational-rotational absorption bands of $\mathrm{CO}_{2}$ in the 4.3 micron spectral region would have to be utilized. The total pumping power from sunlight can be calculated 
from the known data of the solar spectral irradiance outside the atmosphere and the infrared absorption by carbon dioxide at 4.3 microns. The pumping power is proportional to the collector area of the suniight and is also dependent on the characteristics of the absorbing gas mixture, such as the gas composition, the gas temperature, the total pressure of the mixture, the partial pressure of $\mathrm{CO}_{2}$, and the absorption path length of the sunlight in the gas.

To analyze the carbon dioxide laser system, a thermodynamic approach was used with a simplified $\mathrm{CO}_{2}$ chemical kinetic model. The gain and saturation intensity were obtained by solving a set of energy balance equations which describe the processes among the various vibrational modes. From those results, along with the estimated cavity losses, the output power was found.

Initially, the computation was carried out for a $\mathrm{CO}_{2}$-He mixture for the total pressure range 0.01-0.05 atm with various concentrations of $\mathrm{CO}_{2}$ at temperatures of $200^{\circ} \mathrm{K}$ and $300^{\circ} \mathrm{K}$, and with the following system parameters specified: a tube of $100 \mathrm{~cm}$ length and $1.7 \mathrm{~cm}$ diameter, pumping from one end, $1 \%$ residual losses, and a $10 \mathrm{~m}^{2} \mathrm{col}-$ lector. All the collected sunlight was assumed to enter the cavity without losses. Then the parameters were varied to examine their influence on the results. The $10 \mathrm{~m}^{2}$ collector and a $2 \mathrm{~m}$ absorption path length were found to be necessary to achieve sufficient gain and high output power. While the performance was found to be quite sensitive to a number of the individual parameters, the net effect was that the optimum output was obtained under conditions which are close to those initially set. The optimum performance at $200^{\circ} \mathrm{K}$ was obtained 
at 0.02 atm total pressure with $50 \% \mathrm{CO}_{2}$; then the gain was about $5 \% / \mathrm{m}$ and the output power was about 250 milliwatts. The corresponding efficiency of converting absorbed pump light into laser output was about $4 \%$. At $300^{\circ} \mathrm{K}$ the gain was found to be unacceptably low because the lower laser level was more highly populated. Thus, the gas must be cooled to achieve sufficient gain. At total pressures above about 0.05 atm the small signal gain was too low, while at pressures below 0.01 atm the gain and output power decreased on account of the low input power and diffusion effects. Therefore, this particular type of $\mathrm{CO}_{2}$ laser would not appear to be capable of operation at pressures above atmospheric where continuous tunability can be achieved.

This preliminary analysis indicates that it should be feasible to directly sun-pump a carbon dioxide laser in space. The laser would be a modest power, low gain system compared with the demonstrated sun-pumped $\mathrm{Nd}$ :YAG laser. If $\mathrm{CO}_{2}$ output is required or desirable for any of a number of reasons, then this study indicates that direct sunpumping is possible. 
A FEASIBILITY ANALYSIS OF A DIRECTLY

SUN-PUMPED CARBON DIOXIDE LASER IN SPACE

by

SEIICHI MORIMOTO

A thesis submitted in partial fulfiliment of the requirements for the degree of

\author{
MASTER OF SCIENCE \\ in \\ APPLIED SCIENCE
}

Portland State University

1979 
TO THE OFFICE OF GRADUATE STUDIES AND RESEARCH:

The members of the Comnittee approve the thesis of

Seiichi Morimoto presented May 17, 1979.

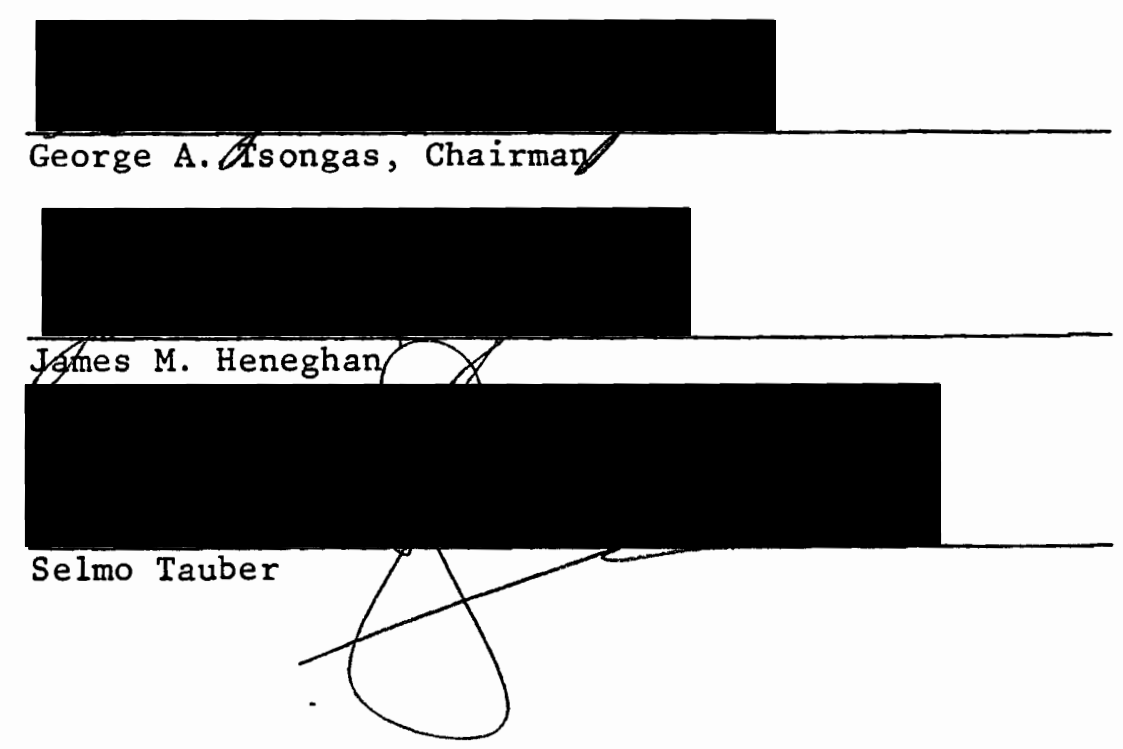

APPROVED:

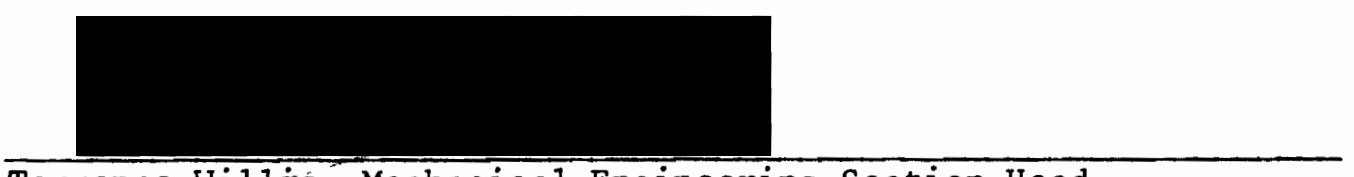

Terrence Wiltis, Department of Engineering and Applied Science

Stanley E. Rauch, Dean of Graduate Studies and Research 


\section{ACKNOWLEDGEMENTS}

The author wishes to express his sincere appreciation to Dr. George Tsongas for his invaluable guidance and unending assistance throughout the course of this study. In addition, his kind and patient contribution of so much time and effort to improve my writing is gratefully appreciated.

It is also a pleasure to acknowledge Dr. Gail Massey of the Oregon Graduate Center and Dr. Walter Christiansen and Dr. Oktay Yesil of the University of Washington for fruitful discussions and helpful suggestions. 
TABLE OF CONTENTS

PAGE

ACKNOWLE DGEMENTS . . . . . . . . . . . . . . . . . . . .

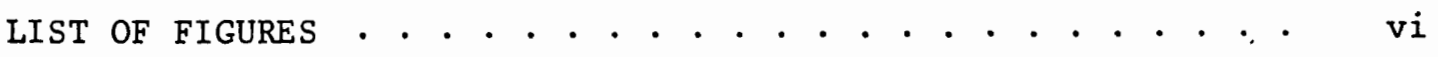

NOMENCLATURE

1. INTRODUCTION . . . . . . . . . . . . . . . . . . 1

2. FEASIBILITY ANALYSIS . . . . . . . . . . . . . . . 4

2.1 SOLAR POWER OUTSIDE THE ATMOSPHERE AND ITS

ABSORPTION BY $\mathrm{CO}_{2}$ MOLECULES

2.2 THEORETICAL MODEL AND CHEMICAL KINETICS OF

CARBON DIOXIDE . . . . . . . . . . . . . 10

2.2.1 Vibrational Energy Levels . . . . . . . . 10

2.2.2 Rotational Energy Levels . . . . . . . . . 14

2.2.3. Vibrational Relaxation . . . . . . . . 16

2.3 PREDICTION OF GAIN AND POWER OUTPUT . • . . . . . . . 22

2.3.1 Minimum Pumping Power Required for

Population Inversion . . . . . . . . . . 22

2.3.2 Gain Coefficient . ... . . . . . . . . 23

2.3.3 Energy Balance Equations . . . . . . . . . . 28

2.3.4 Saturation Intensity and the Maximum Available Power. . . . . . . . . . . 30

2.3.5 Cavity Losses and Output Coupling . . . . . . 31

2.3.6 Threshold Gain and Output Power . . . . . . 32 
3. RESULTS AND DISCUSSION. . . . . . . . . . . . . . . . . . . . 34

3.1 PROPOSED LASER SYSTEM MODEL . . . . . . . . . . . . . . . 35

3.1.1 Description of the System... . . . . . . . . 35

3.1.2 Computed Results for Proposed Laser . . . . . . . 36

3.2 EFFECTS OF PARAMETER VARIATION ON THE SMALI SIGNAL.

GAIN AND THE OUTPUT POWER. . . . . . . . . . . . . . . . 40

3.3. PRACTICAL DESIGN CONSIDERATIONS . . . . . . . . . . . . . . 47

4. CONCLUSIONS . . . . . . . . . . . . . . . . . . . . . . 49

REFERENCES. . . . . . . . . . . . . . . . . . . . . . . 51 


\section{LIST OF FIGURES}

FIGURE

PAGE

1. The Infrared Absorptivity of $\mathrm{CO}_{2}$ in the 4.3 Micron Region at $200^{\circ} \mathrm{K}$ for Various Total Pressures and $\mathrm{CO}_{2}$ Partial Pressures for a 2 Meter Absorption Path Length.

2. Segmentation of the Absorptivity Curve for Calculation of Total Pumping Power

3. Total Pumping Power at $200^{\circ} \mathrm{K}$ for a $10 \mathrm{~m}^{2}$ Collector and

a 2 Meter Absorption Path Length. . . . . . . . . . . . .

4. Total Pumping Power at $300^{\circ} \mathrm{K}$ for a $10 \mathrm{~m}^{2}$ Collector and

a 2 Meter Absorption Path Length. . . . . . . . . . . . 9

5. Partial Energy Level Diagram for Carbon Dioxide . . . . . . 11

6. Temperature Dependence of Relaxation Lifetime of

(010) Leve1 . . . . . . . . . . . . . . . . . .

7. Temperature Dependence of Relaxation Lifetime of

(001) Level . . . . . . . . . . . . . .

8. Simplified Energy Level Diagram . . . . . . . . . . . . . . 28

9. Net Generated Power per Unit Volume Versus Intensity . . . .

10. Variation of Small Signal Gain with Total and Partial 


\section{LIST OF FIGURES (Cont'd)}

FIGURE

PAGE

11. Variation of Output Power with Total and Partial

Pressures . . . . . . . . . . . . . . . . 39

12. Output Power Versus Residual Loss at $200^{\circ} \mathrm{K}$. . . . . . . . . 42

13. Output Power and Small Signal Gain Versus Sun Collector Area at $200^{\circ} \mathrm{K}$. . . . . . . . . . . . . . . . . . 43

14. Output Power and Sma11 Signal Gain Versus Beam Radius at $200^{\circ} \mathrm{K}$. . . . . . . . . . . . . . . . . . 45

15. Output Power and Small Signal Gain Versus Absorption Path Length at $200^{\circ} \mathrm{K}$. . . . . . . . . . . . . . 46

16. Schematic Diagram of a Sun-pumped $\mathrm{CO}_{2}$ Laser with Endpumping . . . . . . . . . . . . . . . . . . . . 47 


\section{NOMENCLATURE}

Eng1 ish :
A
Einstein A coefficient, $\sec ^{-1}$
A
$\mathrm{A}_{\mathrm{S}}$
B
c
$c_{c-k}$
D
$\mathrm{E}_{\mathrm{V}}$
$\overline{\mathrm{E}} \mathrm{V}$
$\mathrm{E}_{1}$
$\mathrm{E}_{2}$
$\mathrm{E}_{3}$
$\mathrm{E}_{12}$
$g(v)$
$g_{J}$
$g_{1}$
$g_{3}$
$\mathrm{h}$
I
$\mathrm{I}_{0}$
Cross-sectional area of the beam, $\mathrm{cm}^{2}$
Area of the sun collector, $\mathrm{cm}^{2}$
Rotational constant, $\mathrm{cm}^{-1}$
Velocity of light, $\mathrm{cm}^{\mathrm{sec}} \mathrm{sec}^{-1}$
The mean relative velocity of $\mathrm{CO}_{2}$ and the species $\mathrm{k}$ ( $\mathrm{C}$ for $\mathrm{CO}_{2}$ and $\mathrm{H}$ for $\mathrm{He}$ ), $\mathrm{m}^{\cdot} \mathrm{sec}^{-1}$
Diffusion constant, $\mathrm{cm}^{2} \cdot$ torr $\cdot \sec ^{-1}$
Vibrational energy per unit volume, $\mathrm{J} \cdot \mathrm{cm}^{-3}$
Vibrational energy in equilibrium, $\mathrm{J} \cdot \mathrm{cm}^{-3}$
Vibrational energy of symmetric mode, $\mathrm{J} \cdot \mathrm{cm}^{-3}$
Vibrational energy of bending mode, $\mathrm{J} \cdot \mathrm{cm}^{-3}$
Vibrational energy of asymmetric mode, $\mathrm{J} \cdot \mathrm{cm}^{-3}$
Combined vibrational energy of $\mathrm{E}_{1}$ and $\mathrm{E}_{2}, \mathrm{~J} \cdot \mathrm{cm}^{-3}$
Lineshape function, sec
Degeneracy of $\mathrm{J}$-th rotational level
Degeneracy of lower vibrational level
Degeneracy of upper vibrational level
Planck's constant $=6.626 \times 10^{-34} \mathrm{~J} \cdot \mathrm{sec}$
Intensity of 1 ight, watts $\cdot \mathrm{cm}^{-2}$
Intensity of incident 1 ight, watts $\cdot \mathrm{cm}^{-2}$ 
inglish:

$I_{s}$

i

$\mathrm{J}$

$J^{\prime}$

k

L

$\mathrm{I}_{i}$

$\ell$

$\ell_{a}$

$\mathrm{m}_{\mathrm{c}}$

$m_{k}$

N

$\mathrm{N}_{\mathrm{k}}$

$N_{i}$

$\mathrm{N}_{1}$

$\mathrm{N}_{3}$

$\mathrm{n}_{\mathrm{J}}$

$n_{1}$

Saturation intensity, watts. $\mathrm{cm}^{-2}$

Vibrationa1 quantum number

Rotational quantum number of the upper level

Rotationa1 quantum number of the lower leve 1

Boltzmann constant $=1.38 \times 10^{-23} \mathrm{~J} \cdot{ }^{\circ} \mathrm{K}^{-1}$

Total intensity loss per pass, \%

Residual intensity loss per pass, \%

Length of the laser tube, $\mathrm{cm}$

Absorption path length of the sunlight, cm

The mass of a $\mathrm{CO}_{2}$ molecule, $\mathrm{kg}$

The mass of a molecule of species $\mathrm{k}, \mathrm{kg}$

Population density of $\mathrm{CO}_{2}$, molecules $\cdot \mathrm{cm}^{-3}$

Population dnesity of species $\mathrm{k}$ ( $\mathrm{C}$ for $\mathrm{CO}_{2}, \mathrm{H}$ for

He), molecules $\mathrm{cm}^{-3}$

i Population density of the $i$-th vibrational level, molecules $\cdot \mathrm{cm}^{-3}$

Population density of the lower vibrational level, molecules $\cdot \mathrm{cm}^{-3}$

Population density of the upper vibrational level, molecules $\cdot \mathrm{cm}^{-3}$

Population density of the $j$-th rotational level, molecules $\cdot \mathrm{cm}^{-3}$

Population density of the vibrational-rotational

lower level, molecules $\mathrm{cm}^{-3}$ 


\section{NOMENCLATURE (Cont'd)}

English:

$\mathrm{n}_{3}$

Population density of the vibrational-rotational

upper level, molecules $\cdot \mathrm{cm}^{-3}$

$P_{\max }$

Maximum available power, watts

$P_{\min }$

Minimum pumping power, watts

$\mathrm{P}_{\mathrm{e}}$

Cavity power (net power generated in the cavity), watts

P

Output power, watts

$\mathrm{P}_{\mathrm{T}}$

Total pumping power, watts

$\mathrm{P}_{\lambda}$

Solar spectral irradiance at 4.3 microns,

watts $\cdot \mathrm{cm}^{-2} \cdot \mu^{-1}$

P

Total pressure of the mixture, atm

$\mathrm{P}_{\mathrm{c}}$

Partial pressure of $\mathrm{CO}_{2}$, atm

Q

Vibrational partition function

$Q_{1}$

Vibrational partition function for symmetric mode

$\mathrm{Q}_{2}$

Vibrational partition function for bending mode

$\mathrm{Q}_{3}$

Vibrational partition function for asymmetric mode

$\mathrm{Q}_{\mathrm{R}}$

Rotational partition function

$\mathrm{R}$

Pumping power density, watts: $\mathrm{cm}^{-3}$

$r$

Radius of the laser tube, $\mathrm{cm}$

$r_{m}$

$\mathrm{T}$

Beam radius, $\mathrm{cm}$

$\mathrm{T}$

Translational temperature (gas temperature), ${ }^{\circ} \mathrm{K}$

Useful mirror transmission, \%

$\mathrm{T}_{\mathrm{V}}$

Vibrational temperature, ${ }^{\circ} \mathrm{K}$

$\mathrm{T}_{1}$

Vibrational temperature of symmetric mode, ${ }^{\circ} \mathrm{K}$

$\mathrm{T}_{2}$

Vibrational temperature of bending mode, ${ }^{\circ} \mathrm{K}$

Vibrational temperature of asymmetric mode, ${ }^{\circ} \mathrm{K}$ 
NOMENCLATURE ( Cont' $d$ )

English :

$\begin{array}{ll}\mathrm{T}_{\mathrm{R}} & \text { Rotational temperature, }{ }_{\mathrm{K}} \\ \mathrm{t}_{\mathrm{sp}} & \text { Spontaneous emission lifetime, sec } \\ \mathrm{V} & \text { Volume of the laser tube, } \mathrm{cm}^{3} \\ \mathrm{v}_{\mathrm{m}} & \text { Volume of the beam, } \mathrm{cm}^{3} \\ \mathrm{v}_{1} & \text { Symmetric stretching mode } \\ \mathrm{v}_{2} & \text { Bending mode } \\ \mathrm{v}_{3} & \text { Asymmetric stretching mode } \\ \mathrm{W} & \text { Induced emmision rate, sec }-1 \\ \mathrm{~W}_{\mathrm{CO}} & \text { The amount of co }{ }_{2} \text { (product of } \mathrm{CO}_{2} \text { partial pressure } \\ & \text { and absorption path length), atm } \mathrm{cm}_{2} \\ \mathrm{z} & \text { The number of collisions required for deactivation } \\ \mathrm{z} & \text { Distance, cm }\end{array}$

Greek:

$\alpha$

$\alpha_{i}$

$\gamma$

$\gamma_{0}$

$\gamma_{t}$

$\varepsilon$

$\varepsilon_{i}$

$\varepsilon_{\mathrm{J}}$

$n$

$\theta_{\mathrm{v}}$

Spectral absorptivity

Spectral absorptivity at a specific wavelength

Gain (gain coefficient), $\mathrm{cm}^{-1}$

Sma11 signal gain, $\mathrm{cm}^{-1}$

Threshold gain, $\mathrm{cm}^{-1}$

Zero-point energy, $\mathrm{J}$

Quantized vibrational energy of $i$-th state, $J$

Quantized rotational energy of $j$-th level, $J$

Energy conversion efficiency

Characteristic temperature for vibration, ${ }^{\circ}{ }_{K}$ 
NOMENCLATURE (Cont' d)

Greek :

$\theta_{1}$

$\theta_{2}$

$\theta_{3}$

$\theta_{\mathrm{R}}$

$\lambda$

$\lambda_{\mathrm{p}}$

$\Delta \lambda$

v

$\bar{v}$

$\nu_{c}$

$\nu_{0}$

$\nu_{\mathrm{p}}$

$\Delta \bar{\nu}$

$\Delta v_{D}$

$\Delta v_{\text {I }}$

$\sigma$

$\sigma$

$c-k$

$\tau$

$\tau_{c}$

${ }^{\tau} \mathrm{C}-\mathrm{C}$

${ }^{\tau} \mathrm{C}-\mathrm{H}$

$\tau_{\operatorname{col1} 1,3}$
Characteristic temperature for symmetric mode $\left(1920^{\circ} \mathrm{K}\right)$

Characteristic temperature for bending mode $\left(960^{\circ} \mathrm{K}\right.$ )

Characteristic temperature for asymmetric mode $\left(3380^{\circ} \mathrm{K}\right.$ )

Characteristic temperature for rotation $\left(.565^{\circ} \mathrm{K}\right)$

Laser wavelength $(\sim 10.6 \mu), \mu$

Pumping wavelength $(\sim 4.3 \mu), \mu$

Spectral interval in wavelength, $\mu$

Frequency, $\mathrm{Hz}$

Wavenumber, $\mathrm{cm}^{-1}$

Collision frequency, $\sec ^{-1}$

Center frequency, $\mathrm{Hz}$

Pumping frequency, $\mathrm{Hz}$

Spectral interval, $\mathrm{cm}^{-1}$

Doppler linewidth, $\mathrm{Hz}$

Lorenzian linewidth, $\mathrm{Hz}$

Optical cross section, $\mathrm{cm}^{2}$

Collision cross section of each species with $\mathrm{CO}_{2}$ (C for $\mathrm{CO}_{2}$ and $\mathrm{H}$ for $\left.\mathrm{He}\right), \mathrm{cm}^{2}$

Relaxation lifetime, sec

Time interval between collisions, sec

Relaxation lifetime by collision with $\mathrm{CO}_{2}$, sec

Relaxation lifetime by collision with He, sec

Collisional relaxation lifetime of uppper laser

level, sec 
NOMENCLATURE (Cont'd)

Greek:

$\begin{array}{ll}\tau_{\mathrm{d}} & \text { Diffusion lifetime, sec } \\ \tau_{\mathrm{rad}} & \text { Radiative lifetime, sec } \\ \tau_{1} & \text { Relaxation lifetime of lower laser level, sec } \\ \tau_{3} & \text { Relaxation lifetime of upper laser level, sec } \\ \psi_{\mathrm{C}} & \text { Fractional concentration of } \mathrm{CO}_{2} \\ \psi_{\mathrm{H}} & \text { Fractional concentration of } \mathrm{He}\end{array}$




\section{INTRODUCTION}

At the present rate of growth, the worldwide space communication demand for new channels will be serious in the near future. The capacity of a communication channel is proportional to the width of its band of frequencies. Thus, a laser emitting in the visible or infrared region of the spectrum, where enormously wide bands of frequencies are available, has the potential to carry many more times the amount of information than radio waves or even microwaves. This is the main reason for wanting to use a laser, but optical communication has another advantageous feature. The spatial coherence of a laser beam makes possible highly directional transmission unattainable by conventional radio techniques, which allows lower transmission losses and at the same time maintains secrecy by preventing easy interception of the signals. Moreover, in space use laser communication is not limited at all by atmospheric scattering, absorption, and turbulence. For many of the same reasons and others, lasers are also of interest for power transmission in space.

In view of the interest in laser communication or power transmission in space, it is natural to consider the possibility of sun-pumping a laser since the external pumping source could possibly be eliminated. A long lifetime and lightweight system might be possible by this pumping approach compared with other conventional pumping methods such as electrical pumping using solar cells or other types of power supplies. One of the most appropriate applications of a space-qualified sun-pumped 
laser would be on a synchronous orbiting satellite which is occluded from the sun during only a small fraction of its orbit.

To date mostly solid state lasers have been studied for sunpumping: Both theoretical and experimental investigations on sunpumping $\mathrm{Nd}: \mathrm{YAG}, \mathrm{Nd}: \mathrm{Glass}, \mathrm{Nd}: \mathrm{CaWO}_{4}$, and ruby lasers have been reported.1-4 Among these candidates, the Nd:YAG laser seems most promising since it is most highly excited above the threshold value for a given sunpumping level and hence has the highest output power. In fact, GTE Sylvania has developed and successfully demonstrated a sun-pumped Nd:YAG laser obtaining about two watts CW output power with a $0.3 \mathrm{~m}^{2}$ collector using an end-pumping method and conductive cooling. 5

However, for both space communication and power transmission other types of lasers including $\mathrm{CO}_{2}$ lasers have been considered. For example, carbon dioxide lasers have several advantages for both applications. First, they are considered to be relatively reliable and long-lived. In addition, high temporal and spatial coherence and outstanding frequency stability compared with solid state lasers is expected. Moreover, $\mathrm{CO}_{2}$ lasers offer a signal-to-noise advantage over Nd:YAG lasers. ${ }^{6}$ Since infrared lasers have a greater beam divergence than visible lasers, their tracking systems need not be as precise. But this fact also means $\mathrm{CO}_{2}$ lasers need more power output. The critical technology problem for a $\mathrm{CO}_{2}$ laser system in space is that of providing Doppler compensation in heterodyne detection systems. 6

Regarding the possibility of sun-pumping carbon dioxide, the $\mathrm{CO}_{2}$ molecule has intense and wide vibration-rotational absorption bands in the 4.3 micron region, among others. It is those bands that would have 
to be utilized to optically pump $\mathrm{CO}_{2}$. Actually the feasibility of achieving considerable power by optical excitation of a $\mathrm{CO}_{2}$ laser by its own radiation and also by blackbody radiation was hypothesized by Bokhan. ${ }^{7,8}$ In fact, he experimentally proved optical pumping to be practical by obtaining one watt of laser power for a $\mathrm{CO}_{2}$ (50 Torr) - $\mathrm{N}_{2}(1 \mathrm{~atm})$ mixture with radiation from the hot combustion process of $\mathrm{CO}$ in oxygen providing the pump light. ${ }^{9}$ Similar work was done by Wieder. ${ }^{10}$ More recently Yesil and Christiansen ${ }^{11}$ and others ${ }^{12}$ have measured gain in a $\mathrm{CO}_{2}$ gas mixture optically pumped by blackbody radiation in an effort to demonstrate the feasibility of solar pumping. In addition, Chang and Wood optically pumped a $\mathrm{CO}_{2}$ laser with a pulsed $\mathrm{HBr}$ laser and produced a peak power of a few kilowatts for pulses of about $2.2 \mathrm{nsec}$ using extremely high pressure (33 atm) pure $\mathrm{CO}_{2}$.

However, the possibility of using the sun to directly pump $\mathrm{CO}_{2}$ has not previously been pursued. Yet it would be extremely beneficial to know whether such pumping is feasible, and if so to what degree. How might its performance compare with that of the Nd:YAG sun-pumped laser? Thus, the objective of this study is to analyze the feasibility of a directly sun-pumped $\mathrm{CO}_{2}$ laser for space application. To do that, a simplified theoretical model of such a $\mathrm{CO}_{2}$ laser is developed, as described in the chapters to follow. 


\section{FEASIBILITY ANALYSIS}

\subsection{SOLAR POWER OUTSIDE THE ATMOSPHERE AND ITS ABSORPTION BY $\mathrm{CO}_{2}$}

\section{MOLECULES}

In order to determine whether a carbon dioxide laser can be pumped using sunlight, two questions must be answered:

1. In what spectral region does carbon dioxide absorb light for pumping?

2. Is enough sunlight available in that region to achieve sufficient gain and power output, given the absorption characteristics of $\mathrm{CO}_{2}$ ?

As noted earlier, carbon dioxide absorbs incident light strongly in the 4.3 micron region. Thus, the amount of solar power available at that wavelength must be determined. Although a great deal of solar spectrum data is available for the visible region, beyond 2.4 mircons no complete spectrum has been obtained outside (or inside) the atmosphere. However, it is similar to that of a $6000^{\circ} \mathrm{K}$ gray-body and can be extrapolated from the known data for shorter wavelengths. From a table of solar spectral irradiance data ${ }^{15}$ so determined, the spectral irradiance (defined as the incident radiant energy $f l u x$ per unit surface area per unit spectral interval) outside the atmosphere for the 4.3 micron region is given as $\mathrm{P}_{\lambda}=0.00073$ watts $\mathrm{cm}^{-2} \mu^{-1}$. With the available solar power known, the absorption of the sunlight by carbon dioxide must be considered. The infrared absorptivity (the fraction of the incident radiation absorbed) of carbon dioxide 
at 4.3 microns has been calculated for a wide range of values of absorption path length, pressure, and temperature. $16,17 *$

Here some typical values of the spectral absorptivity $\alpha$ are plotted in Figure 1 for various total pressures $p$ and partial pressures of carbon dioxide $\mathrm{p}_{\mathrm{c}}$; the absorption path length of the sunlight $l_{a}$ is taken to be 2 meters (round trip path in a $1 \mathrm{~m}$ tube is assumed). ${ }^{* *}$ clearly, there is more absorption at high pressures where more absorbing molecules exist. Pressures higher than those given are not presented because they will be shown to correspond to non-optimum laser performance.

Assuming no losses transmitting the incident sunlight into the cavity (in reality some loss factor would exist), the total solar pumping power $\mathrm{P}_{\mathrm{T}}$ into a given cavity can be calculated from the following expression (see Figure 2):

$$
\mathrm{P}_{\mathrm{T}}=\mathrm{P}_{\lambda} \mathrm{A}_{\mathrm{s}} \sum_{i} \alpha_{i} \Delta \lambda
$$

where

$\mathrm{P}_{\lambda}$ : solar power at $4.3 \mu$ per unit area per unit spectral intervals (watts $\mathrm{cm}^{-2} \mu^{-1}$ )

$A_{S}:$ sun collector area $\left(\mathrm{cm}^{2}\right)$

$\alpha_{i}$ : spectral absorptivity of $\mathrm{CO}_{2}$ at $\lambda_{i}$, where $\lambda_{i}$ is the center wavelength of the $i$-th spectral segment

* In references 16 and 17 absorption data are for $\mathrm{CO}_{2}$ in air (i.e. almost a $\mathrm{CO}_{2}-\mathrm{N}_{2}$ gas mixture), but it can be shown that these data can be used for a $\mathrm{CO}_{2}$-He gas mixture as well with an error of less than a few percent. The reason is that broadening caused by $\mathrm{N}_{2}$ is not very much different from that caused by He when either is in a mixture with $\mathrm{CO}_{2}$. In addition, variation of total pumping power with broadening is even much smaller than that of broadening itself.

** The data from references 16 and 17 were actually tabulated for various $\mathrm{p}$ and $\mathrm{W}_{\mathrm{CO}_{2}}$, where $\mathrm{W}_{\mathrm{CO}_{2}}=\mathrm{P}_{\mathrm{c}}{ }^{\ell}{ }_{\mathrm{a}}$. 


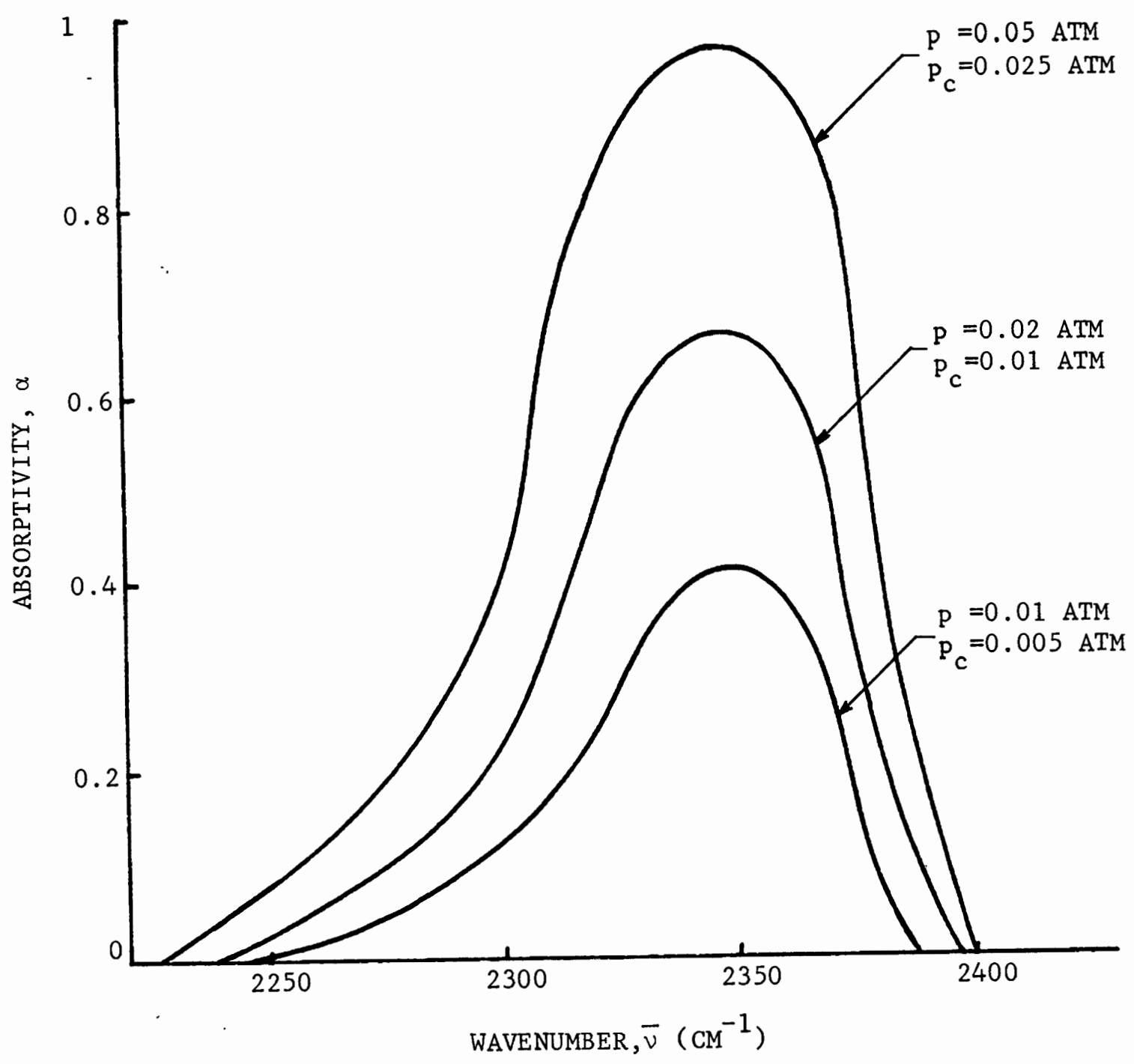

Figure 1. The infrared absorptivity of $\mathrm{CO}_{2}$ in the 4.3 micron region at $200^{\circ} \mathrm{K}$ for various total pressures $\mathrm{p}$ and $\mathrm{CO}_{2}$ partial pressures $\mathrm{p}_{\mathrm{c}}$ for a 2 meter absorption path length. 
$\Delta \lambda: \quad$ spectral interval of the given absorptivity data * ( $\mu)$ It should be noted that this procedure for the determination of $\mathrm{P}_{\mathrm{T}}$ is used because the absorptivity data is provided in tabular form at discrete wavelength intervals.

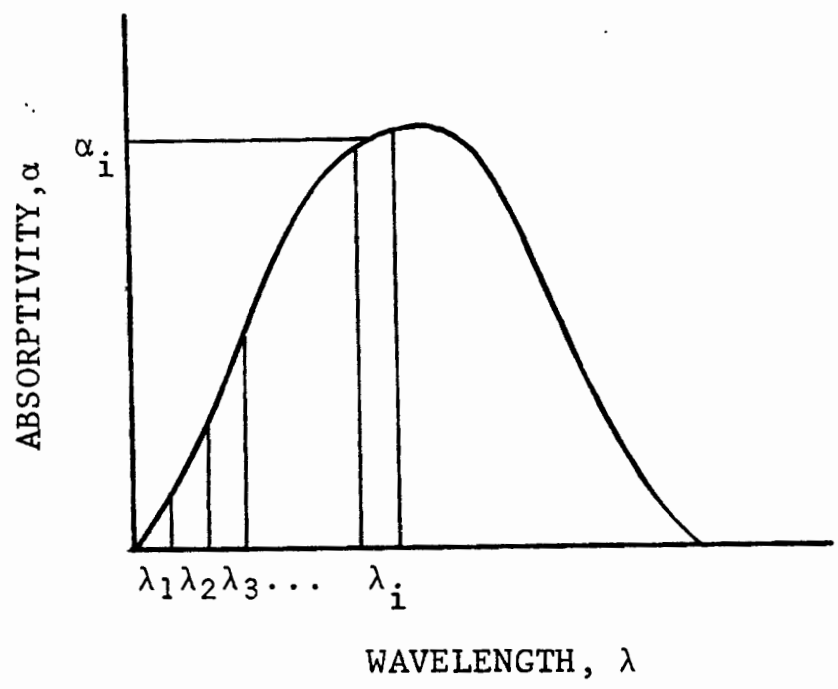

Figure 2. Segmentation of the Absorptivity Curve for Calculation of $\mathrm{P}_{\mathrm{T}}$.

Using equation ( 1 ) and the absorptivity data, $P_{T}$ was calculated.

The results are plotted in Figures 3 and 4 versus $10 g \mathrm{P}_{\mathrm{c}}$ (where $\ell_{\mathrm{a}}=2 \mathrm{~m}$ ) for each $\mathrm{P}$ for the temperatures $200^{\circ} \mathrm{K}$ and $300^{\circ} \mathrm{K}$, respectively. ${ }^{* *}$ These temperatures will later be shown to be in the range of prime importance for laser action.

It can be seen from the graphs that $\mathrm{P}_{\mathrm{T}}$ increases with temperature (15-20\% increase in $\mathrm{P}_{\mathrm{T}}$ from $200^{\circ} \mathrm{K}$ to $\left.300^{\circ} \mathrm{K}\right)$, and the variation of $\mathrm{P}_{\mathrm{T}}$ with $p_{c}$ is fairly logarithmic.

* $\Delta \lambda=0.018 \mu$, which corresponds to $\Delta \bar{\nu}=10 \mathrm{~cm}^{-1}$.

** The horizontal scale $\log \mathrm{P}_{\mathrm{c}}$ is actually $\log \mathrm{W}_{\mathrm{CO}_{2}}$ with fixed value of $\ell_{a}=2 \mathrm{~m}$. P $P_{T}$ for values of $\ell_{a}$ other than $2 \mathrm{~m}^{2} \mathrm{can} b \mathrm{be}$ found easily from the relation $\mathrm{W}_{\mathrm{CO}_{2}}=\ell_{a} \mathrm{P}_{\mathrm{c}}$. 


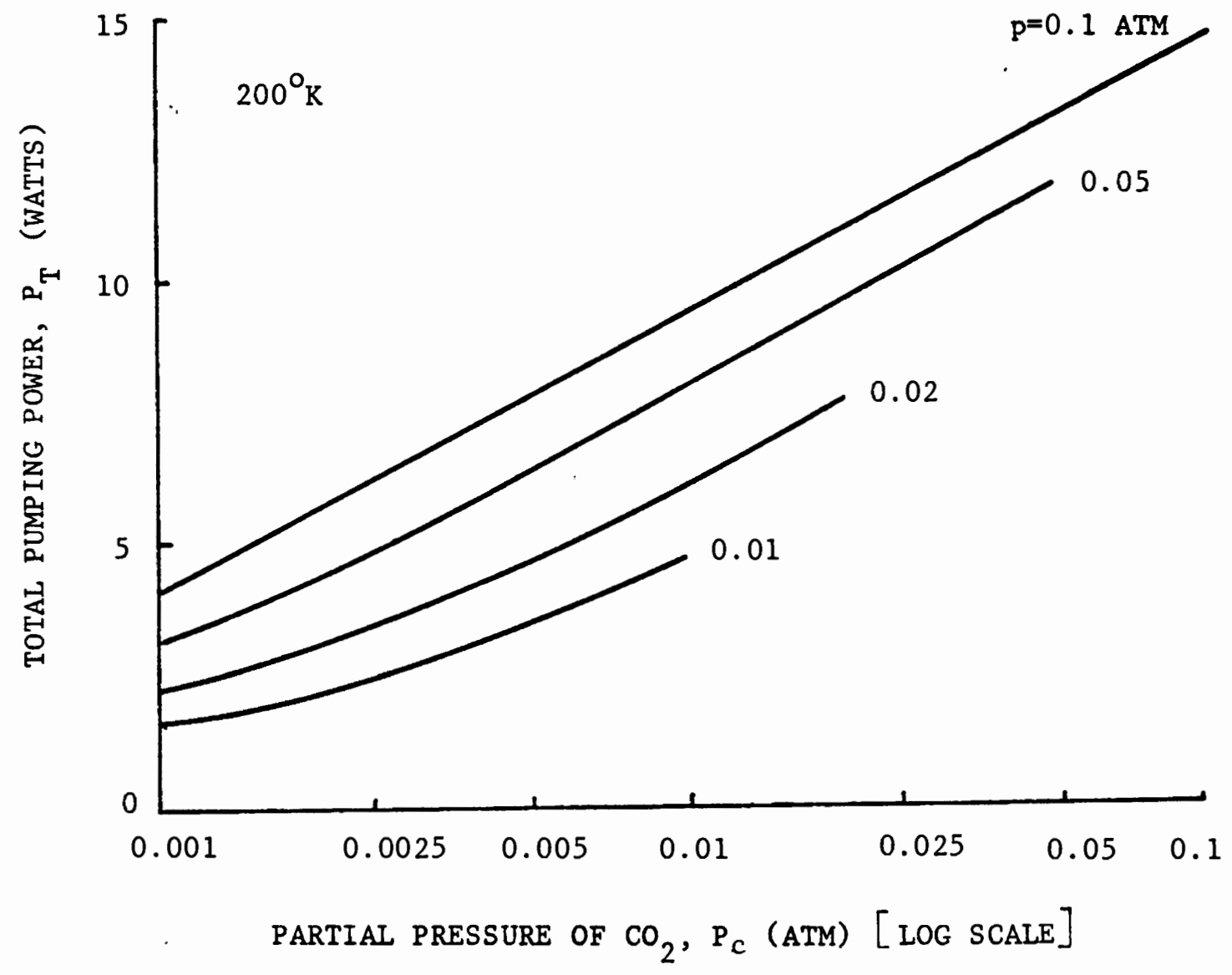

Figure 3. Total pumping power, $\mathrm{P}_{\mathrm{T}}$, at $200^{\circ} \mathrm{K}$ for a $10 \mathrm{~m}^{2}$ collector and a 2 meter absorption path length. 


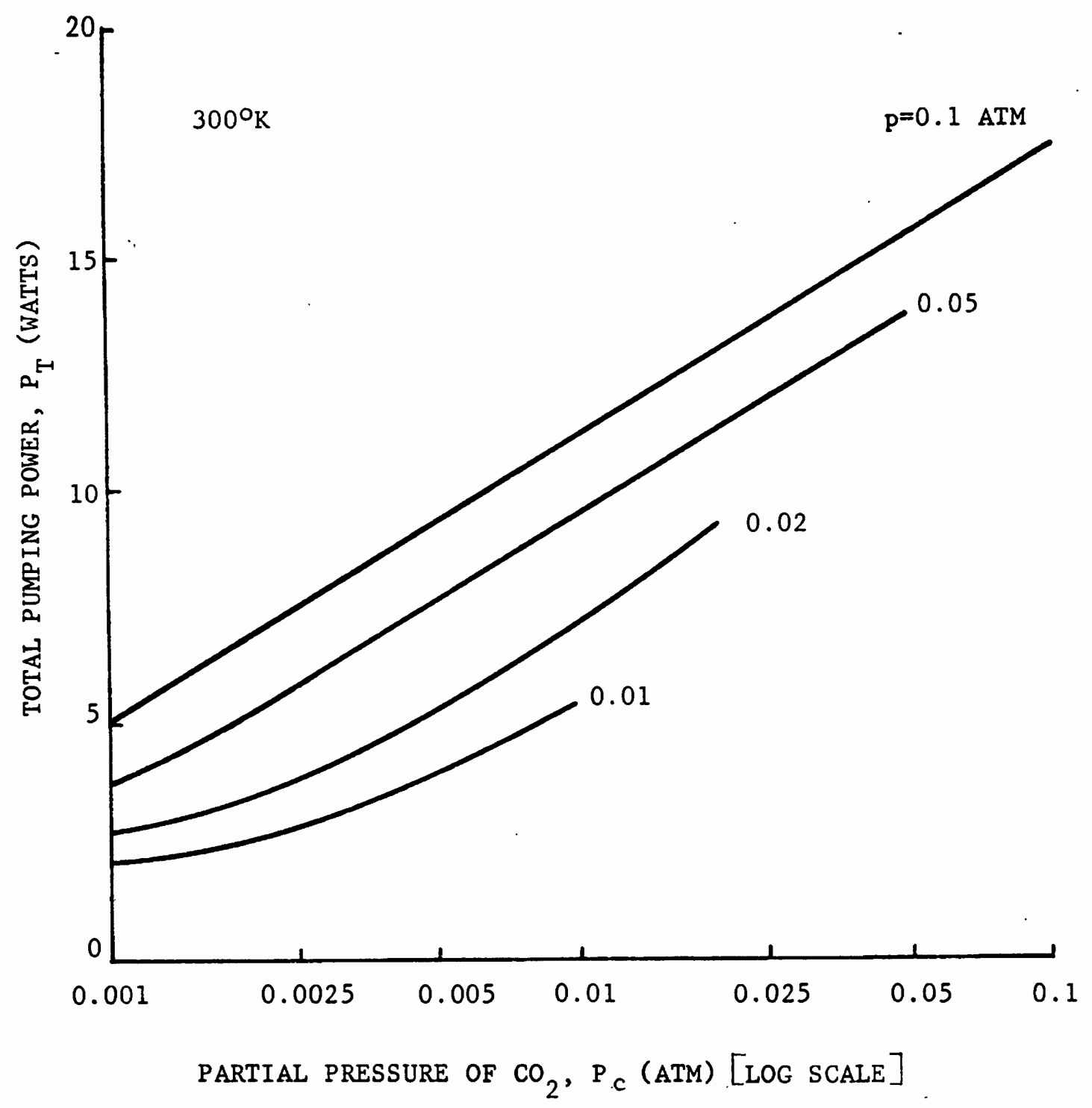

Figure 4. Total pumping power, $\mathrm{P}_{\mathrm{T}}$, at $300^{\circ} \mathrm{K}$ for a $10 \mathrm{~m}^{2}$ collector and a 2 meter absorption path length. 


\subsection{THEORETICAL MODEL AND CHEMICAL KINETICS OF CARBON DIOXIDE}

Since a thermodynamic approach will be used later to analyze the carbon dioxide laser system, it will be appropriate to present here some fundamental facts about vibrational and rotational levels of $\mathrm{CO}_{2}$ and the relaxation processes among the vibrational levels. This includes specific equations for the energy of the vibrational modes, for the population of vibrational and rotational levels, and for the relaxation lifetimes of vibrational states. These equations will be later used to directly calculate the gain and saturation intensity of the sun-pumped $\mathrm{CO}_{2}$ gas mixture, as well as the laser output power.

Carbon dioxide is a linear symmetrical molecule which has three normal modes of vibration:
the symmetric stretching mode
$v_{1} \quad\left(i_{1} \quad 0 \quad 0\right)$
the doubly degenerate bending mode
$v_{2} \quad\left(\begin{array}{lll}0 & i_{2} & 0\end{array}\right)$
the asymmetric stretching mode
$v_{3} \quad\left(\begin{array}{lll}0 & 0 & i_{3}\end{array}\right)$

where $i_{1}, i_{2}, i_{3}=0,1,2,3, \ldots$ specify the vibrational states. A partial energy level diagram for the carbon dioxide molecule is illustrated in Figure 5. Shown are the pertinent vibrational energy levels together with a set of rotational levels for the $\left(\begin{array}{lll}1 & 0 & 0\end{array}\right)$ and the $\left(\begin{array}{lll}0 & 0 & 1\end{array}\right)$ states on a much expanded scale. The 10.6 micron laser transition and some principal relaxation processes are shown in the diagram.

\subsubsection{Vibrational Energy Levels}

The molecules may be regarded to a good approximation as harmonic oscillators of frequency $\nu$. According to quantum mechanics, the 


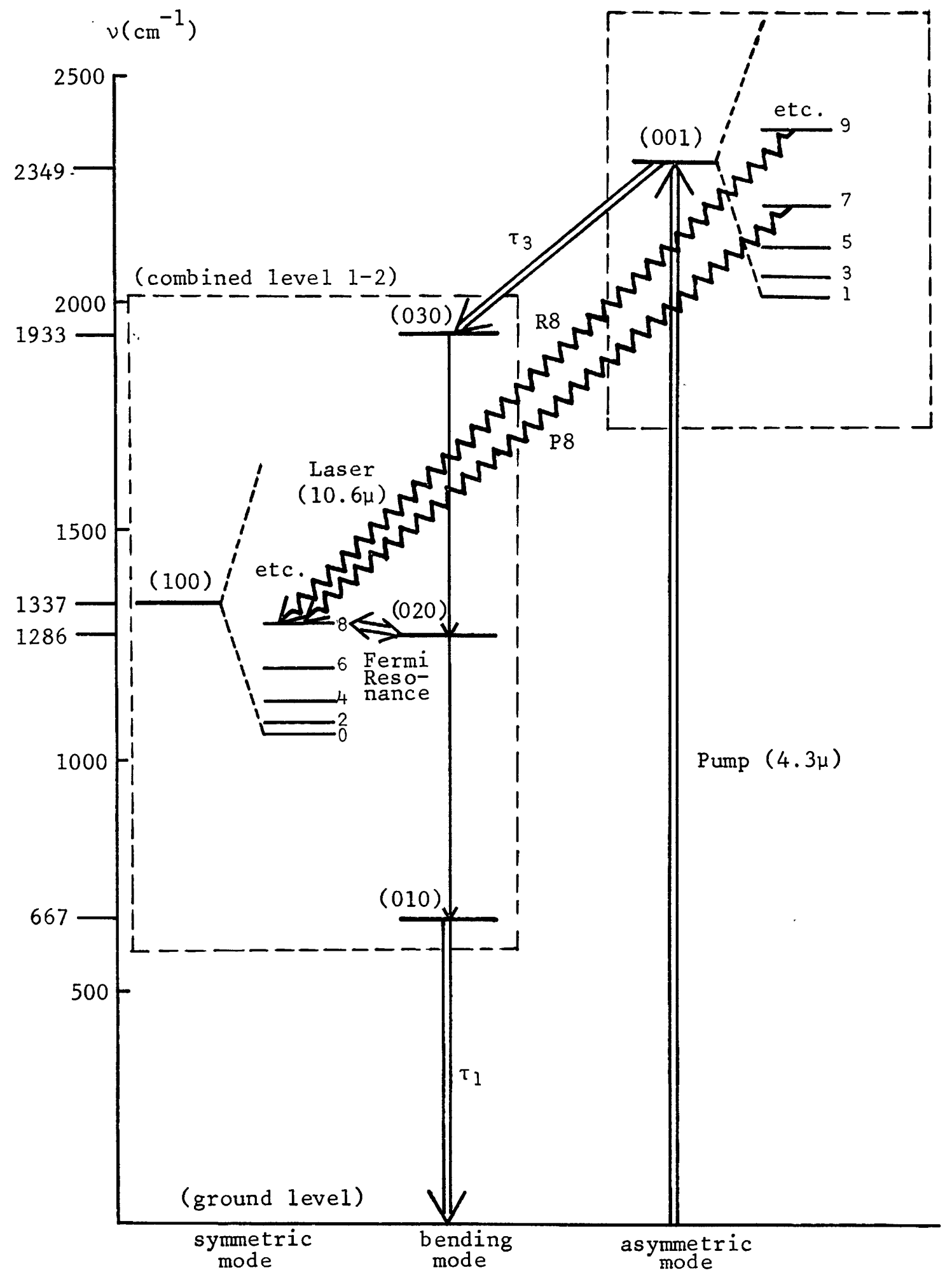

Figure 5. Partial energy level diagram for $\mathrm{CO}_{2}$. 
degrees of vibrational excitation are quantized and the permissible energy states of a molecule are given by

$$
\varepsilon_{i}=\left(i+\frac{1}{2}\right) h \nu \quad \text { where } i=0,1,2,3, \ldots .
$$

Omitting the zero-point energy $\varepsilon_{0}=\frac{1}{2}$ h $\nu$ of a vibrational ground state (i.e. vibrational energies are measured from the ground state),

$$
\varepsilon_{i}=\text { ihv where } i=0,1,2,3, \ldots .
$$

Now the vibrational partition function is introduced (i.e. how the particles are partitioned or divided up among the energy states), as defined by

$$
Q_{v}=\sum_{i=0}^{\infty} \exp \left(-\varepsilon_{i} / k T_{v}\right)=\sum_{i=0}^{\infty} \exp \left(-i h \nu / k T_{v}\right)
$$

where $T_{v}$ is the vibrational temperature. That temperature is, in effect, defined in the Einstein function of equation (7) below. When $T_{v}=T$ (gas temperature), a thermodymanic non-equilibrium condition exists. Note that $\mathrm{T}_{\mathrm{v}}$ (and $\mathrm{E}_{\mathrm{v}}$ shown later) indicates the degree of population of a certain vibrational state; the higher the vibrational temperature, the larger the population of the vibrational state.

The sum in equation (4) is recognized as the geometrical series

$$
Q_{v}=1 /\left[1-\exp \left(-\theta_{v} / T_{v}\right)\right]
$$

where

$\theta_{\mathrm{v}}=\mathrm{h} \nu / \mathrm{k}$ : characteristic temperature for vibration Using equation (5) and the relation 18

$$
E_{v}=N k T_{v}^{2} \frac{\partial \cdot \ln Q_{v}}{\partial T_{v}}
$$

where $\mathrm{N}$ is the total population density of $\mathrm{CO}_{2}$, the total vibrational energy of the oscillators per unit volume is

$$
E_{v}=N k \theta_{v} /\left[\exp \left(\theta_{v} / T_{v}\right)-1\right]
$$


This is the well known Einstein function (in terms of vibrational temperature $\mathrm{T}_{\mathrm{v}}$ ) for a simple harmonic oscillator with a Boltzmann distribution of the states.

When $\mathrm{T}_{\mathrm{v}}$ is in equilibrium with the translational temperature $\mathrm{T}$ (i.e. $\mathrm{T}_{\mathrm{v}}=\mathrm{T}$ ),

$$
\overline{\mathrm{E}}_{\mathrm{v}}=\mathrm{Nk} \theta_{\mathrm{v}} /\left[\exp _{\mathrm{P}}\left(\theta_{\mathrm{v}} / \mathrm{T}\right)-1\right]
$$

The population distribution for the i-th vibrational level is given by the formula 18

$$
N_{i} / N=\exp \left(-i \theta_{v} / T_{v}\right) / Q_{v}
$$

where

$$
\begin{aligned}
& N_{i}: \text { population density of the } i \text {-th vibrational level } \\
& N \text { : total population density }
\end{aligned}
$$

Now, from the ideal gas law

$$
\mathrm{N}\left(\text { molecules } / \mathrm{cm}^{3}\right)=7.37 \times 10^{2} \mathrm{p}_{\mathrm{c}}(\mathrm{atm}) / \mathrm{T}\left({ }^{\mathrm{O}} \mathrm{K}\right)
$$

So far we have been referring to one vibrational mode. However, since carbon dioxide has three modes, the vibrational partition function $Q_{v}$ for $\mathrm{CO}_{2}$ is (taking the double degeneracy of the bending mode into account)

$$
\begin{aligned}
Q_{v} & =Q_{1} Q_{2}^{2} Q_{3} \\
& =\left\{\left[1-\exp \left(-\theta_{1} / T_{1}\right)\left[1-\exp \left(-\theta_{2} / T_{2}\right)\right]^{2}\left[1-\exp \left(-\theta_{3} / T_{3}\right)\right]\right\}^{-1}\right.
\end{aligned}
$$

where $Q_{1}, Q_{2}$, and $Q_{3}$ correspond to the $v_{1}, v_{2}$, and $v_{3}$ modes, respectively. Then, the energies of the three modes are, respectively,

$$
\begin{aligned}
& \mathrm{E}_{1}=\mathrm{NkT}_{1}^{2}\left(\partial \ln \mathrm{Q}_{\mathrm{v}} / \partial \mathrm{T}_{1}\right)=\mathrm{Nk}_{1} /\left[\exp \left(\theta_{1} / \mathrm{T}_{1}\right)-1\right] \text { for } \mathrm{v}_{1} \text { mode } \\
& \mathrm{E}_{2}=\mathrm{NkT}_{2}^{2}\left(\partial \ln \mathrm{Q}_{\mathrm{v}} / \partial \mathrm{T}_{2}\right)=2 \mathrm{Nk} \theta_{2} /\left[\exp \left(\theta_{2} / \mathrm{T}_{2}\right)-1\right] \text { for } \mathrm{v}_{2} \text { mode } \\
& \mathrm{E}_{3}=\mathrm{NkT}_{3}^{2}\left(\partial \ln _{\mathrm{v}} / \partial \mathrm{T}_{3}\right)=\mathrm{Nk}_{3} /\left[\exp \left(\theta_{3} / \mathrm{T}_{3}\right)-1\right] \text { for } \mathrm{v}_{3} \text { mode } \\
&
\end{aligned}
$$


where $\mathrm{T}_{1}, \mathrm{~T}_{2}$, and $\mathrm{T}_{3}$ are the vibrational temperatures of the $\mathrm{v}_{1}, \mathrm{v}_{2}$, and $v_{3}$ modes, respectively, and $\theta_{1}, \theta_{2}$, and $\theta_{3}$ are the characteristic temperatures of vibration of the $v_{1}, v_{2}$, and $v_{3}$ modes, respectively.

\subsubsection{Rotationa1 Energy Levels}

Each vibrational level is subdivided into a number of rotational levels denoted by J's. J can only be odd or even numbers for a given vibrational level, and the selection rule for rotational transitions is $\mathrm{J}= \pm 1$ ( $\mathrm{J}=+1$ is a P-transition; $\mathrm{J}=-1$ is an $\mathrm{R}$-transition).

The quantized rotational energy is given by

$$
\varepsilon_{\mathrm{J}}=\mathrm{hcBJ}(\mathrm{J}+1)
$$

where

$$
\begin{aligned}
& \mathrm{J}=0,1,2,3, \ldots \ldots \\
& \mathrm{B}=\text { rotational constant for each vibrational state }
\end{aligned}
$$

Taking the degeneracy $g_{J}(=2 J+1)$ into account, the rotational partition function is

$$
\begin{aligned}
& Q_{R}=\sum_{J=0}^{\infty} g_{J} \exp \left(-\varepsilon_{J} / k T_{R}\right) \\
& \cdot=\sum_{J=0 \text { even or odd }}^{\infty}(2 \mathrm{~J}+1) \exp \left[-\mathrm{J}(\mathrm{J}+1) \mathrm{hcB} / \mathrm{kT}_{\mathrm{R}}\right] \\
& \mathrm{J}=\text { even or odd }
\end{aligned}
$$

By approximating the series by an integral for a linear and symmetric molecule like $\mathrm{CO}_{2}$,

$$
Q_{R}=\frac{1}{2} \int_{0}^{\infty} d J(2 J+1) \exp \left[-J(J+1) h c B / k T_{R}\right]
$$

which can be shown to be 18

$$
\mathrm{Q}_{\mathrm{R}}=\mathrm{T}_{\mathrm{R}} / 2 \theta_{\mathrm{R}}
$$


where

$$
\begin{aligned}
\theta_{R} & =h c B / k: \text { characteristic temperature for rotation } \\
T_{R} & =\text { rotational temperature }
\end{aligned}
$$

Among the various rotational levels of a vibrational level a Boltzmann distribution in terms of the gas temperature $T\left(=T_{R}\right)$ is established, which results from the fact that the spacing of the rotational energy levels is comparable to the kinetic energy $(0.025 \mathrm{eV})$ of a molecule and these energies are easily exchanged in collisions (thermalization).

Hence, at gas temperature $T\left(=T_{R}\right)$ the population of the $J$-th rotational level is determined by 18

$$
\mathrm{n}_{J}=\mathrm{g}_{\mathrm{J}} \mathrm{N}_{i}\left\{\exp \left[-\mathrm{J}(\mathrm{J}+1) \theta_{\mathrm{R}} / \mathrm{T}\right]\right\} / Q_{R}
$$

where

$$
\begin{aligned}
\mathrm{n}_{\mathrm{J}}= & \text { population density of the } \mathrm{J} \text {-th vibrational- } \\
& \text { rotational leve } 1
\end{aligned}
$$

By differentiating this equation with respect to $J$, the value of $\mathrm{J}$ for which $\mathrm{n}_{\mathrm{J}}$ is maximum is given by

$$
\mathrm{J}_{\max }=\sqrt{\mathrm{kT} / 2 \mathrm{hcB}}-\frac{1}{2} \simeq 0.95 \sqrt{\mathrm{T}}-\frac{1}{2}
$$

where $B \simeq 0.39 \mathrm{~cm}^{-1}$ for (100) and (001). ${ }^{19}$

The maximum gain occurs when using this expression for $\mathrm{J}_{\max }$; the value of $J_{\max }$ at those temperatures where the gain will be evaluated is as follows.

AT $\mathrm{T}=200^{\circ} \mathrm{K}$

$$
\mathrm{J}_{\max }=13 \quad \text { i.e. } \mathrm{J}=13, \mathrm{~J}^{\prime}=14 \quad \text { for } \mathrm{P}(14)
$$

At $\mathrm{T}=300^{\circ} \mathrm{K}$

$$
\mathrm{J}_{\max }=16 \quad \text { i.e. } \mathrm{J}=15, \mathrm{~J}^{\prime}=16 \quad \text { for } \mathrm{P}(16)
$$




\subsubsection{Vibrational Relaxation}

Excited molecules in vibrational levels will decay in three different fashions: by radiative decay (spontaneous emmission), collisional deactivation and spatial diffusion. Over the pressure range of interest in this study, the latter two processes are dominant since the radiative decay lifetimes are considerably larger than the corrsponding collision or diffusion lifetimes. *

One means of effectively raising the relaxation rate at which molecules start or cease to interact with the lasing field is by diffusions of molecules into and out of the laser beam (i.e. the region in the gas where amplification exists). Diffusion can play an important role in laser beams with both small radii and low total pressure. An expression for the diffusion lifetime $\tau_{d}$ is found to be $21-23$

$$
\frac{1}{\tau_{d}(\mathrm{sec})}=\frac{8 \mathrm{D}}{\mathrm{p}(\text { torr }) \mathrm{r}_{\mathrm{m}}^{2}(\mathrm{~cm})\left[1+4 \ell \mathrm{n}\left(\mathrm{r} / \mathrm{r}_{\mathrm{m}}\right)\right]} \frac{\mathrm{T}\left({ }^{\circ} \mathrm{K}\right)}{300}
$$

For a $\mathrm{CO}_{2}$-He mixture where $\mathrm{D}=400 \mathrm{~cm}$ torr $/ \mathrm{sec}^{23}$, the expression becomes

$$
\tau_{d}(\mathrm{sec})=\frac{71 \mathrm{p}(\mathrm{atm}) \mathrm{r}_{\mathrm{m}}^{2}(\mathrm{~cm})\left[1+4 \mathrm{ln}\left(\mathrm{r} / \mathrm{r}_{\mathrm{m}}\right)\right]}{\mathrm{T}\left({ }^{\mathrm{O}} \mathrm{K}\right)}
$$

where

$$
\begin{aligned}
& D \text { : diffusion constant } \\
& r_{m} \text { : beam radius } \\
& r \text { : radius of the tube }
\end{aligned}
$$

* The radiative Iifetime $\tau_{\mathrm{rad}}$ is about $2.5 \mathrm{msec}$ for the (001) (100) transition (all P-transitions and $R$ transitions), while for other transitions it is much larger. 20 
The second important deactivation process is collisional relaxation. Since this is the dominant process for the pressure range of interest in this study (i.e. $p=0.01-0.05 \mathrm{~atm}$ ), the rest of our discussion will be concerned with the detailed mechanism of collisional relaxation.

Transfer of energy between two vibrational states or one vibrational and one translational degree of freedom occurs through molecular collisions. The collisional relaxation lifetime $\tau$ (which is the average time for a molecule to exist in an excited state before deactivation) is defined by

$$
\tau=\tau_{c} z
$$

where

$\tau_{c}$ : the time interval between collisions, which is inversely proportional to pressure

$\mathrm{Z}$ : the average number of collisions to deactivate one vibrational quantum to its $e^{-1}$ value (i.e. $1 / Z$ is the probability of deactivation of vibrational energy in one collision)

In a mixture involving $\mathrm{CO}_{2}$ and the foreign gas He (as noted later, this mixture is chosen for our laser system), relaxation of a vibrationally excited $\mathrm{CO}_{2}$ molecule can take place through binary collision processes with either ground state $\mathrm{CO}_{2}$ molecule or with a He atom. The relaxation rate for binary collisions is given by 24,25

$$
\frac{1}{\mathrm{p} \tau}=\frac{\psi_{\mathrm{C}}}{\mathrm{p} \tau{ }_{\mathrm{C}-\mathrm{C}}}+\frac{\psi_{\mathrm{H}}}{\mathrm{p}{ }_{\mathrm{C}-\mathrm{H}}}
$$

where

$$
{ }^{\tau}{ }_{C-C}: \text { relaxation lifetime for collisions with } \mathrm{CO}_{2}
$$


$\tau_{\mathrm{C}-\mathrm{H}}$ : relaxation lifetime for collisions with He

$1 / \mathrm{P}{ }_{\mathrm{C}-\mathrm{C}}$ : relaxation rate for pure $\mathrm{CO}_{2}$ at $\mathrm{p}$ atm pressure

$1 / \mathrm{p}^{\tau}{ }_{\mathrm{C}-\mathrm{H}}$ : relaxation rate for collisions with He at $\mathrm{p}$ atm pressure

$\psi_{\mathrm{C}}$ and $\psi_{\mathrm{H}}$ : mole fractions of $\mathrm{CO}_{2}$ and $\mathrm{He}$, respectively

$$
\left(\psi_{\mathrm{C}}+\psi_{\mathrm{H}}=1\right)
$$

In what follows the kinetic reactions and the values of the 1 ifetimes $\tau_{C-C}$ and $\tau_{C-H}$ for the pertinent levels will be examined. In modeling the important kinetic processes involved in a $\mathrm{CO}_{2}$ laser, certain simplifications have been made as shown in the diagram of Figure 5 . It has been assumed that V - V (vibrational - vibrational) transitions are very fast in each mode (i.e. in the vertical direction, such as (030) $\rightarrow$ $(020),(020) \rightarrow(010)$, but not from one mode to any other (i.e. in the horizontal direction). It should, however, be noted that process $(100) \neq(020)$ is very rapid because of the known Fermi resonance (F.R.). Therefore, with this simplified model, mode $v_{1}$ and $v_{2}$ are considered to be one combined level 1-2. Then, the rate-controlling processes among the groups of vibrational levels (i.e. level 3, combined leve1 1-2, and the ground leve1) are those from (001) to level 1-2 (i.e. lifetime $\tau_{3}$ ) and from level (010) to ground level (i.e. lifetime $\tau_{1}$ ).

The pertinent processes for energy transfer between the noted vibrational states can be expressed as kinetic reactions as follows:

$T$ - V (translational - vibrational) processes:

$$
\mathrm{CO}_{2}(010)+\mathrm{CO}_{2} \stackrel{\tau_{1}, \mathrm{C}-\mathrm{C}}{\longrightarrow} \mathrm{CO}_{2}+\mathrm{CO}_{2}+667 \mathrm{~cm}^{-1}
$$




$$
\mathrm{CO}_{2}(010)+\mathrm{He} \stackrel{\tau_{1}, \mathrm{C}-\mathrm{H}}{\longrightarrow} \mathrm{CO}_{2}+\mathrm{He}+667 \mathrm{~cm}^{-1}
$$

V - V (vibrational - vibrationa1) processes:

$$
\begin{aligned}
& \mathrm{CO}_{2}(001)+\mathrm{CO}_{2} \stackrel{\tau_{3}, \mathrm{C}-\mathrm{C}}{\longrightarrow} \mathrm{CO}_{2}(030)+\mathrm{CO}_{2}+416 \mathrm{~cm}^{-1} \quad(27 \mathrm{c})^{*} \\
& \mathrm{CO}_{2}(001)+\mathrm{He} \stackrel{\stackrel{3}{3} \mathrm{C}-\mathrm{H}}{\longrightarrow} \mathrm{CO}_{2}(030)+\mathrm{He}+416 \mathrm{~cm}^{-1}
\end{aligned}
$$

Crucial to laser oscillation is the fact that the lifetime of the upper level $\tau_{3}$ must be larger than the lifetime of the lower level $\tau_{1}$. Only then can a population inversion be achieved. Furthermore, the population inversion could be increased by enhancing the lower level depopulation rate with the addition of helium.

The values of the collisional relaxation lifetimes $\tau_{3, C-C}, \tau_{3, C-H}$ $\tau_{1, C-C}$ and $\tau_{1, C-H}$ for the kinetic processes noted above have previously been measured experimentally and are plotted versus temperature for convenience in Figures 6 and 7. 24,26-29 The lifetimes vary inversely with pressure.

Now, since the diffusion effect on the upper level is considerable and radiative decay is not negligible in the lowest pressure range of this study, a combined lifetime $\tau_{3}$ which incroporates all of these effects must be used; it is given as:

$$
\frac{1}{\tau_{3}}=\frac{1}{\tau_{d, 3}}+\frac{1}{\tau_{\operatorname{col} 1,3}}+\frac{1}{\tau_{\operatorname{rad}, 3}}
$$

Note that the $\tau_{3}$ referred to earlier was really $\tau_{\text {coll, }} 3^{\text {. The values }}$ of $\tau_{d, 3}$ are calculated using equation (24).

* Reactions (27c) and (27d) are considered to be dominant for the relaxation process from (001) to the 1-2 level. However, since those from (001) to any other levels in the 1-2 level could be responsible, $\tau_{3}, C-C$ and $\tau_{3}, C-H$ should be understood to correspond to the process from (001) to the whole 1-2 level. 


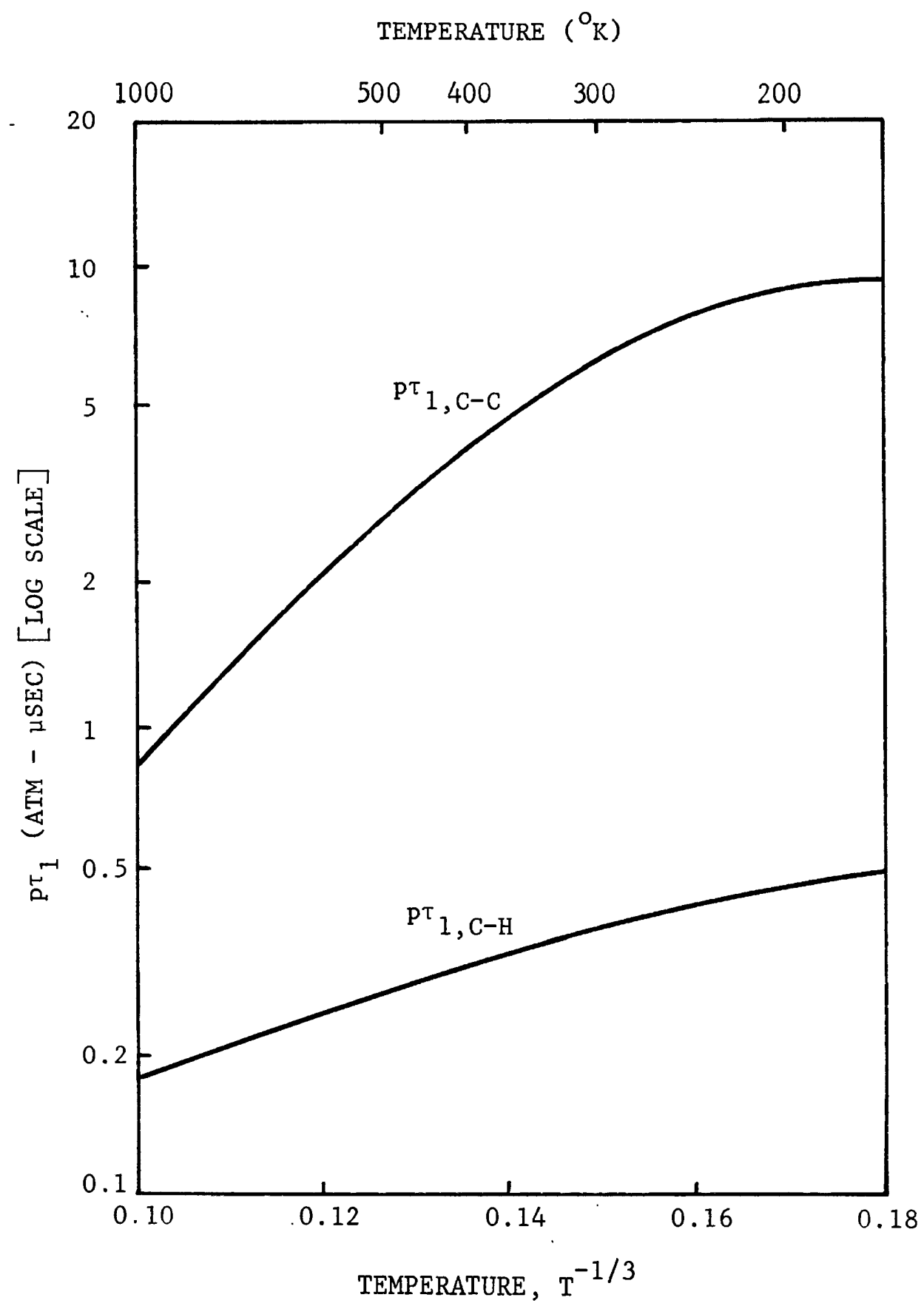

Figure 6. Temperature dependence of the relaxation lifetime of the (010) level, $\tau_{1} .24,26-29$ 


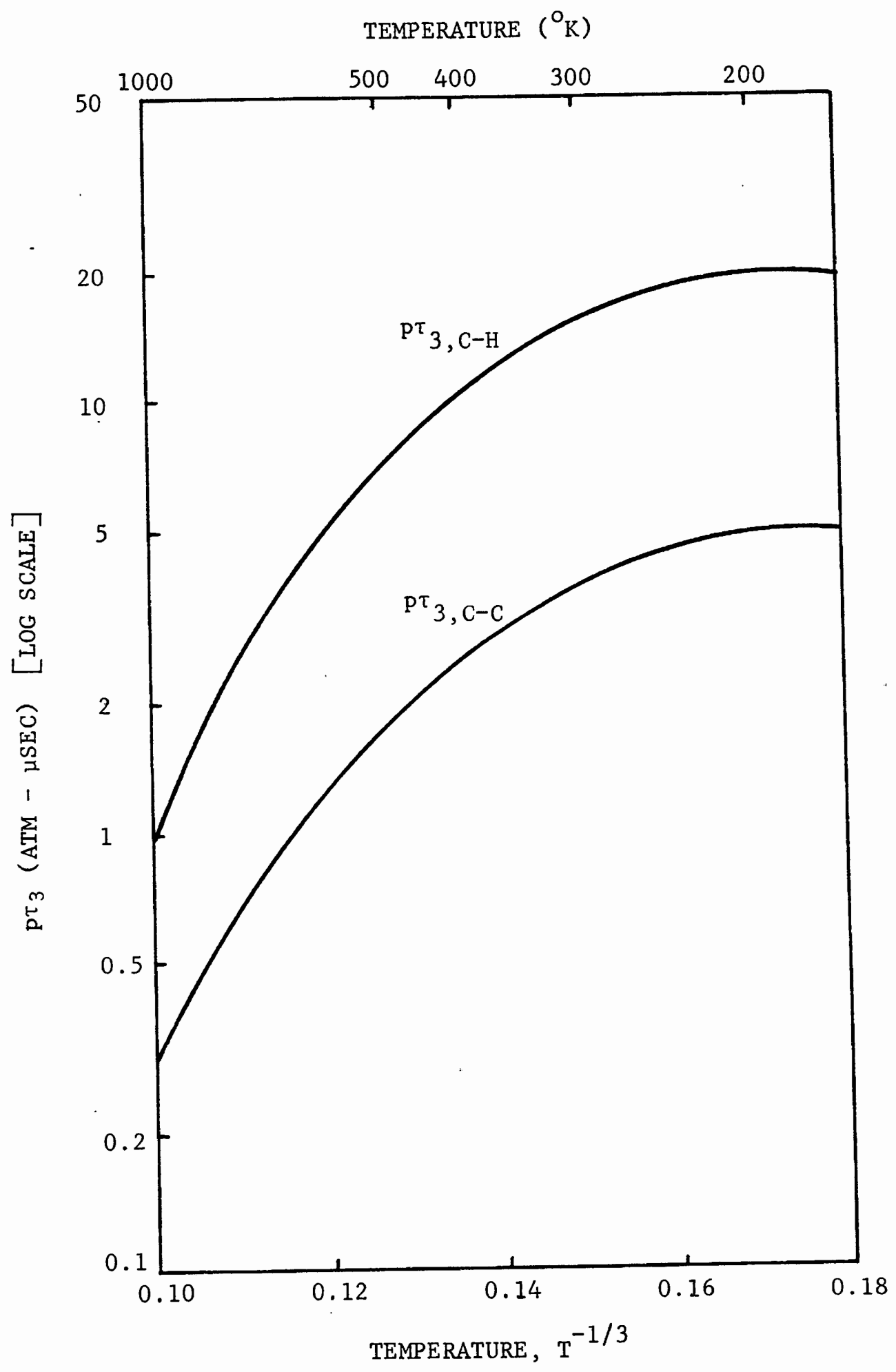

Figure 7. Temperature dependence of the relaxation lifetime of the (001) level, $\tau_{3} .24,26-29$ 
Therefore, combining the quations (24) and (26)

$$
\begin{aligned}
\frac{1}{\tau_{3}} & =\frac{\mathrm{T}\left(\mathrm{O}_{\mathrm{K}}\right)}{71 \mathrm{p}(\mathrm{atm}) \mathrm{r}_{\mathrm{m}}^{2}(\mathrm{~cm})[1+4 \mathrm{ln}(\mathrm{r} / \mathrm{rm})]} \\
& +\left[\frac{\psi_{\mathrm{C}}}{\mathrm{p} \tau_{3, \mathrm{C}-\mathrm{C}}}+\frac{\psi_{\mathrm{H}}}{\mathrm{p} \tau_{3, \mathrm{C}-\mathrm{H}}}\right] \mathrm{p}(\mathrm{atm})+\frac{1}{2.5 \times 10^{-3}}
\end{aligned}
$$

where

$$
\begin{aligned}
& \mathrm{P}_{3, \mathrm{C}-\mathrm{C}}=3.76 \mathrm{~atm} \mu \mathrm{sec} \text { at } 300^{\circ} \mathrm{K} \\
& \mathrm{P \tau}_{3, \mathrm{C}-\mathrm{H}}=15.5 \mathrm{~atm} \mu \mathrm{sec} \text { at } 300^{\circ} \mathrm{K}
\end{aligned}
$$

The values of $\mathrm{P}_{3, \mathrm{C}-\mathrm{C}}$ and $\mathrm{P}_{3, \mathrm{C}-\mathrm{H}}$ for $200^{\circ} \mathrm{K}$ are 1.2 times those of $300^{\circ} \mathrm{K}$.

Thus, in summary the pertinent mode energies, level populations, and relaxation rates are functionally available to predict the actual laser gain and the power output for a given set of conditions. The necessary gain and output power relations which require the expressions presented in this section are discussed in the following section.

\subsection{PREDICTION OF GAIN AND POWER OUTPUT}

\subsubsection{Minimum Pumping Power Reguired for Population Inversion}

When an electromagnetic field is applied to atoms (or molecules), the interaction between the field and the atoms results in absorption or stimulated emission depending upon the relative population in the upper and lower levels. For any collection of atoms in thermal equilibrium, there are always more atoms in a lower energy level than in a higher energy level, and the transition is absorptive. 
The essential feature of laser action is that under proper circumstances, by pumping or exciting the atoms in appropriate fashion, a nonequilibrium condition can be created which produces a temporary "population inversion" such that Boltzmann's law in terms of gas temperature does not apply. In order to achieve a population inversion the available total pumping power, $\mathrm{P}_{\mathrm{T}}$, must be greater than some minimum pumping power, $\mathrm{P}_{\min }$, where $\mathrm{P}_{\min }$ is given by 7

$$
P_{\min }=\frac{N_{1} V h \nu_{p}}{\tau_{3}}
$$

where

$$
\nu_{p}=c / \lambda_{p}=c / 4 \cdot 3 \mu=\text { pumping frequency }
$$

Thus,

where

$$
R>\frac{N_{1} h \nu_{p}}{\tau_{3}}
$$

$$
\mathrm{R}=\mathrm{P}_{\mathrm{T}} / \mathrm{V} \cdot=\text { pumping power density }
$$

In terms of vibrational temperatures, the following relation has to be satisfied for population inversion of the vibrational levels,

so that

$$
\frac{N_{3}}{N_{1}}=\frac{N e^{-\theta_{3} / T_{1}} / Q_{v}}{N^{-\theta_{1} / T_{1} / Q_{v}}}>1
$$

$$
\frac{\mathrm{T}_{3}}{\mathrm{~T}_{1}}>\frac{\theta_{3}}{\theta_{1}}=1.76
$$

Relations (31) and (33) will be useful to roughly check the possibility of achieving lasing action.

\subsubsection{Gain Coefficient}

Electromagnetic radiation of intensity I propagating through an 
amplifying medium (where a population inversion exists) with a gain coefficient $\gamma$ will be amplified with an increase per unit length

$$
\frac{d I}{d z}=\gamma I
$$

Or integrating

$$
I(z)=I_{0} e^{\gamma z}
$$

That is, the intensity grows exponentially.

From the principle of energy conservation, the increase in intensity per unit length, $d I / d z$, is equal to the net power generated per unit volume of length $\mathrm{d} z, i, e$,

$$
\gamma I=g_{3}\left(\frac{n_{3}}{g_{3}}-\frac{n_{1}}{g_{1}}\right) \text { Whv }
$$

where $W$, the induced emission rate, is given by

with

$$
W=\frac{\lambda^{2} I \cdot \dot{g}(\nu)}{8 \pi h \nu t_{s p}}=\frac{\sigma I}{h \nu}
$$

$\sigma \quad:$ optical cross section

$g(\nu):$ line shape

$g_{3}, g_{1}$ : degeneracy of rotational levels of upper and lower vibrational levels, respectively

$$
\begin{aligned}
& \mathrm{g}_{3}=2 \mathrm{~J}+1, \mathrm{~g}_{1}=2 \mathrm{~J}^{\prime}+1 \\
& \mathrm{~J}^{\prime}=\mathrm{J}+1 \text { for P-transitions (strongest gain) }
\end{aligned}
$$

$\mathrm{n}_{3}, \mathrm{n}_{1}$ : vibrational-rotational populations of upper and lower levels, respectively $\left(\mathrm{cm}^{-3}\right)$

Therefore, the expression of gain is obtained as

where

$$
\gamma=\frac{\lambda^{2} g(v)}{8 \pi t_{s p}} g_{3}\left(\frac{n_{3}}{g_{3}}-\frac{n_{1}}{g_{1}}\right)=\sigma g_{3}\left(\frac{n_{3}}{g_{3}}-\frac{n_{1}}{g_{1}}\right)
$$

$$
\begin{aligned}
t_{s p}: & \text { spontaneous emission lifetime }\left(t_{s p}\right. \text { for the P-1aser tran- } \\
& \text { sition at } 10.6 \mu \text { is } 5.38 \mathrm{sec})^{30}
\end{aligned}
$$


$g(v)$ : lineshape function which describes the distribution

of emitted intensity versus the frequency $v$; it is

$$
\text { normalized according to } \int_{-\infty}^{+\infty} g(\nu) d \nu=1
$$

For the pressure broadening case (which applies to most of the pressure range in this study),

$$
g\left(\nu_{0}\right)=\frac{\Delta \nu_{L}}{2 \pi\left[\left(\nu-\nu_{0}\right)^{2}+\left(\Delta \nu_{L} / 2\right)^{2}\right]}=\frac{2}{\pi \Delta \nu_{L}} \quad\left(\text { since } \nu=\nu_{0}\right)
$$

where $\Delta v_{L}$ is the Lorentzian linewidth which is given by the equation

$$
\Delta \nu_{L}=\frac{1}{\pi \tau_{C}}=\frac{\nu_{C}}{\pi}
$$

The collision frequency $\nu_{c}$ for $\mathrm{CO}_{2}$ is in general given by

$$
\nu_{c}=\sum_{k} N_{k} \sigma_{c-k} \bar{c}_{c-k}
$$

where

$\mathrm{N}_{\mathrm{k}} \quad$ : the population of each species

$\sigma_{c-k}$ : the collision cross section of each species with $\mathrm{CO}_{2}$

$\bar{c}_{c-k}$ : the mean relative velocity of the species

$$
\bar{c}_{c-k}=\sqrt{\frac{8 k T}{\pi m}}, \frac{1}{m}=\frac{1}{m_{c}}+\frac{1}{m_{k}}
$$

$\mathrm{m}_{\mathrm{k}}$ : the mass of a molecule of each species

$\mathrm{m}_{\mathrm{c}}$ : the mass of a $\mathrm{CO}_{2}$ molecule

In the case of a $\mathrm{CO}_{2}$-He mixture

$$
\nu_{c}=\mathrm{N}_{\mathrm{C}} \sigma_{\mathrm{C}-\mathrm{C}} \overline{\mathrm{c}}_{\mathrm{C}-\mathrm{C}}+\mathrm{N}_{\mathrm{H}} \sigma_{\mathrm{C}-\mathrm{H}} \bar{c}_{\mathrm{C}-\mathrm{H}}
$$

While the above can in general be used to calculate $\Delta \nu_{L}$, experimental values of $\sigma_{\mathrm{C}-\mathrm{H}}$ are required. Recent experiments have resulted in the following formulation 31

$$
\Delta \nu_{L}=\left(9.96 \times 10^{10}\right)\left(\psi_{c}+0.64 \psi_{H}\right)
$$

The results obtained by using equation (43) are in good accord with the results obtained by using the more general equations noted above. 
For the combined Doppler and pressure broadening case (Voigt Profile), ${ }^{32,33}$ which applies to the lowest pressure range of this study,

where

$$
g\left(\dot{\nu}_{0}\right)=\frac{2 \sqrt{\ln 2}}{\sqrt{\pi} \Delta \nu_{D}} \exp \left(x^{2}\right) \operatorname{erfc}(x)
$$

$\Delta \nu_{D}:$ Doppler Linewidth $=\left(3.05 \times 10^{6}\right) \sqrt{\mathrm{T}} \mathrm{Hz}$ for a $\mathrm{CO}_{2}$ line

$$
\mathrm{x}=\sqrt{\ln 2} \Delta \nu_{L} / \Delta \nu_{D}
$$

erfc(x) : complimentary error function, whose values are

$$
\begin{aligned}
& \text { tabulated or given by } \\
& \operatorname{erfc}(\mathrm{x})=\frac{2}{\sqrt{\pi}} \int_{x}^{\infty} \mathrm{du} \mathrm{e}^{-\mathrm{u}^{2}}
\end{aligned}
$$

It is easily verified that the lineshape function reduces to the results for pure Doppler or pressure broadening, if the limit $x \rightarrow$ 0 or $x \rightarrow \infty$ is taken in equation (44):

1) Doppler broadened limit: $x \rightarrow 0$

$$
g\left(\nu_{0}\right) \rightarrow \frac{2 \sqrt{\ln 2}}{\sqrt{\pi} \Delta v}
$$

2) Pressure broadened limit: $x \rightarrow \infty$

$$
g\left(\nu_{0}\right) \rightarrow \frac{2}{\pi \Delta \nu_{L}}
$$

where the asymptotic relation $\exp \left(x^{2}\right): \operatorname{erfc}(x) \stackrel{\dot{\rightarrow}}{\rightarrow} 1 /(x \sqrt{\pi})$ was used.

Now recalling the relations for rotational and vibrational populations, as given by equations (21) and (9), the rotational and vibrational populations of the upper and lower levels are given by

$$
\begin{aligned}
& \frac{n_{3}}{g_{3} N_{3}}=\frac{e^{-J(J+1) \theta_{R} / T}}{Q_{R}} \\
& \frac{n_{1}}{g_{1} N_{1}}=\frac{e^{-J^{\prime}\left(J^{\prime}+1\right) \theta_{R} / T}}{Q_{R}}
\end{aligned}
$$




$$
\begin{aligned}
& \mathrm{N}_{3}=\frac{\mathrm{N} \mathrm{e}^{-\theta_{3} / T_{3}}}{\mathrm{Q}_{\mathrm{v}}}=\frac{\xi_{3}}{\mathrm{Q}_{\mathrm{v}}} \frac{\mathrm{E}_{3}}{\mathrm{k} \theta_{3}} \\
& \mathrm{~N}_{1}=\frac{\mathrm{N} \mathrm{e}^{-\theta_{1} / \mathrm{T}_{1}}}{\mathrm{Q}_{\mathrm{v}}}=\frac{\xi_{1}}{\mathrm{Q}_{\mathrm{v}}} \frac{\mathrm{E}_{12}}{\mathrm{k} \theta_{1}}
\end{aligned}
$$

where

$\mathrm{N}$ : total $\mathrm{CO}_{2}$ population

$\mathrm{N}_{3}, \mathrm{~N}_{1}$ : population densities of the upper and lower vibrational levels, respectively

$n_{3}, n_{1}$ : population densities of the upper and lower rotationalvibrational levels, respectively

$\mathrm{T}_{3}, \mathrm{~T}_{1}$ : vibrational temperatures of the upper and lower levels, respectively

and where

$$
\begin{aligned}
& E_{3}=N k \theta_{3} /\left[e^{\theta_{3} / T_{3}}-1\right] \\
& E_{12}=E_{1}+E_{2}=N k \theta_{1} /\left\{1 /\left[e^{\theta_{1} / T_{1}}-1\right]+1 /\left[e^{\theta_{2} / T_{1}}-1\right]\right\} \\
& \xi_{3}=\left[1-e^{-\theta_{3} / T_{3}}\right] \\
& \xi_{1}=e^{-\theta_{1} / T_{1} /\left[\left(e^{\theta_{1} / T_{1}}-1\right)^{-1}+\left(e^{\theta_{2} / T_{1}}-1\right)^{-1}\right]} \\
& Q_{v}=\left[\left(1-e^{-\theta_{1} / T_{1}}\right)\left(1-e^{-\theta_{2} / T_{1}}\right)^{2}\left(1-e^{-\theta_{3} / T_{3}}\right)\right]^{-1} \\
& T_{2} \text { is assumed equal to } T_{1} \text { (by Fermi resonance). }
\end{aligned}
$$

Hence, the gain can be expressed in terms of the energies of the modes characterized by the vibrational temperatures as follows

$$
\begin{aligned}
\gamma & =\frac{\lambda^{2} g(\nu)}{8 \pi t_{s p}} g_{3}\left(\frac{n_{3}}{g_{3}}-\frac{n_{1}}{g_{1}}\right) \\
& =\frac{\lambda^{2} g(\nu)}{8 \pi t_{s p}} g_{3}\left(\frac{n_{3}}{g_{3} N_{3}} N_{3}-\frac{n_{1}}{g_{1} n_{1}} N_{1}\right) \\
& \simeq\left(\frac{G_{0}}{N}\right)\left(N_{3}-N_{1}\right)\left(\text { since } \frac{n_{3}}{g_{3} N_{3}} \simeq \frac{n_{1}}{g_{1} N_{1}}\right) \\
\gamma & =\left(\frac{G_{O}}{N}\right) \frac{1}{k Q_{v}}\left[\frac{\xi_{3}}{\theta_{3}} E_{3}-\frac{\xi_{1}}{\theta_{1}} E_{12}\right]
\end{aligned}
$$

where

$$
\left(\frac{G_{O}}{N}\right)=\frac{\lambda^{2} g(\nu)}{8 \pi t_{s p}} g_{3} \frac{e^{-J(J+1) \theta R / T}}{Q_{R}}
$$




\subsubsection{Energy Balance Equations}

In order to find $E_{3}$ and $E_{12}$ and to get the final form of the gain expression, a set of energy balance equations among the vibrational modes will be introduced. Figure 8 below is the simplified energy level diagram for the energy equations.

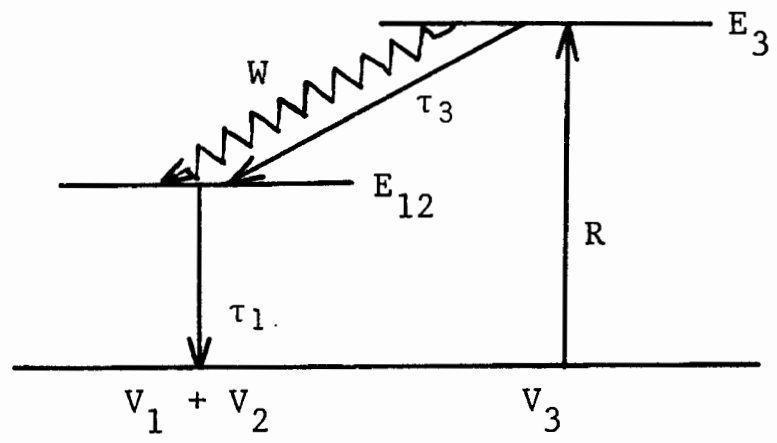

Figure 8. Simplified Energy Level Diagram.

Knowing that vibrational energy will always tend toward the equilibrium value and that the energy relaxation rate is expressed as $\frac{d E_{\mathbf{v}}}{d t}=\frac{E_{\mathbf{v}}-\bar{E}_{\mathbf{v}}}{\tau}$, energy equations for the three modes in steady state are 30

$$
\begin{aligned}
\frac{d E_{3}}{d t}= & R-\frac{1}{\tau_{3}}\left[E_{3}-\bar{E}_{3}\right]-\frac{\theta_{3}}{\theta_{3}-\theta_{1}} g_{3}\left(\frac{n_{3}}{g_{3}}-\frac{n_{1}}{g_{1}}\right) \text { Wh } \nu=0 \\
\frac{d E_{12}}{d t} & =\frac{1}{\tau_{3}} \frac{3 \theta 2}{\theta_{3}}\left[E_{3}-\bar{E}_{3}\right]-\frac{1}{\tau_{1}}\left[E_{12}-\bar{E}_{12}\right] \\
& +\frac{\theta_{1}}{\theta_{3}-\theta_{1}} g_{3}\left(\frac{n_{3}}{g_{3}}-\frac{n_{1}}{g_{1}}\right) \text { Wh } \nu=0
\end{aligned}
$$

where

$$
g_{3}\left(\frac{g_{3}}{g_{3}}-\frac{n_{1}}{g_{1}}\right) W h \nu=\gamma I
$$

However, $\bar{E}_{3} \simeq 0$ since the thermal population of the upper level is negligible compared with the pumped population. Then the equations for the energy balance and the gain are

$$
R-\frac{E_{3}}{\tau_{3}}-\frac{\theta_{3}}{\theta_{3}-\theta_{1}} \gamma I=0
$$




$$
\begin{aligned}
& \frac{1}{\tau_{3}} \frac{3 \theta_{2}}{\theta_{3}} E_{3}-\frac{1}{\tau_{1}}\left[E_{12}-\bar{E}_{12}\right]+\frac{\theta_{1}}{\theta_{3}-\theta_{1}} \gamma_{I}=0 \\
& \gamma=\left(\frac{G_{0}}{N}\right) \frac{1}{k Q_{v}}\left[\frac{\xi_{3}}{\theta_{3}} E_{3}-\frac{\xi_{1}}{\theta_{1}} E_{12}\right]
\end{aligned}
$$

Thus, there are the three unknowns $E_{3}, E_{12}, \gamma$ in the three equations above; solving for $\gamma$,

$$
\gamma=\frac{\left(\frac{G_{0}}{N}\right) \frac{1}{\mathrm{kQ}_{\mathrm{V}}}\left[\left(\frac{\xi_{3}}{\theta_{3}} \tau_{3}-\frac{3}{2} \frac{\xi_{1}}{\theta_{3}} \tau_{1}\right) R-\frac{\xi_{1}}{\theta_{1}} \bar{E}_{12}\right]}{\left.1+\left(\frac{G_{0}}{N}\right) \frac{1}{\mathrm{kQ}_{\mathrm{v}}} \mathrm{I}\left[\frac{\xi_{3}}{\theta_{3}-\theta_{1}} \tau_{3}-\frac{\xi_{1}}{2\left(\theta_{3}-\theta_{1}\right.}\right)_{1}\right]}
$$

This is the general expression for the gain in terms of $T_{3}, T_{1}$, and $I$. For a small signal (where $I \simeq 0$ ) in the energy equations, (64), (65), and (60)

$$
E_{3}=\tau_{3} R=\frac{N k \theta_{3}}{e^{\theta_{3} / T_{3}}-1}
$$

Therefore

$$
T_{3}=\frac{\theta_{3}}{\ln \left(\frac{N k \theta_{3}}{\tau_{3} R}+1\right)}
$$

Also,

$$
\begin{aligned}
{\left[E_{12}-\bar{E}_{12}\right] } & =\frac{3 \theta_{2}}{\theta_{3}} \tau_{1} R \\
& =\frac{k N \theta_{1}}{\xi_{1}} e^{-\dot{\theta}_{1} / T_{1}}-\frac{k N \theta_{1}}{\xi_{1}} e^{-\theta_{1} / T_{1}}
\end{aligned}
$$

where

$$
\xi_{1}^{\prime}=e^{-\theta_{1} / T} /\left[\left(e^{\theta_{1} / T}-1\right)^{-1}+\left(e^{\theta_{2} / T}-1\right)^{-1}\right]
$$

therefore

$$
T_{1}=\frac{\theta_{2}}{\ln \left(\frac{1 \pm \sqrt{4 \beta^{2}+8 \beta+1}}{2 \beta}\right)}
$$

where

$$
\beta=\frac{1}{k N}\left(\frac{3}{2 \theta_{3}} \tau_{1} R\right)+\left(e^{\theta_{1} / T}-1\right)^{-1}+\left(e^{\theta_{2} / T}-1\right)^{-1}
$$

The small signal gain $\gamma_{0}$ is.

$$
\begin{aligned}
\gamma_{0} & =\left(\frac{G_{0}}{N}\right) \frac{1}{k Q_{v}}\left[\frac{\xi_{3}}{\theta_{3}} E_{3}-\frac{\xi_{1}}{\theta_{1}} E_{12}\right] \\
& =\left(\frac{G_{0}}{N}\right) \frac{1}{k Q_{v}}\left[\left(\frac{\xi_{3}}{\theta_{3}} \tau_{3}-\frac{3}{2} \frac{\xi_{1}}{\theta_{3}} \tau_{1}\right) R-\frac{\xi_{1}}{\theta_{1}} \bar{E}_{12}\right]
\end{aligned}
$$


Thus, for a small signal $(I \simeq 0)$, the values of the vibrational temperatures $T_{3}, T_{1}$ and the gain (small signal gain) $\gamma_{0}$ can be calculated from equations (68), (71), and (73).

\subsubsection{Saturation Intensity and the Maximum Available Power}

When a population inversion is created in a laser such that an electromagnetic field (laser oscillation) builds up, the presence of that field reduces the population inversion and hence the gain coefficient. This effect is called gain saturation and is the mechanism which reduces the gain inside laser oscillators to a point where it just balances the losses so that steady oscillation can result. The maximum power of any laser is limited by saturation of the gain.

In a homogeneously broadened (pressure broadened) case, " the gain profile is uniformly saturated and the coefficient decreases with radiation intensity $I$ according to the relation

$$
\gamma=\frac{\gamma_{0}}{1+\frac{I}{I_{s}}}
$$

where $I_{s}$, the saturation intensity, defined as the intensity level that causes the inversion (and therefore the gain) to drop to one-half of its unsaturated value, will be given by comparing the gain expression obtained previously (equation (66)) and equation (74), i.e.

$$
I_{s}=\frac{k Q_{y}}{\left(\frac{G o}{N}\right)} \frac{1}{\left[\frac{\xi_{3}}{\theta_{3}-\theta_{1}} \tau_{3}-\frac{\xi_{1}}{2\left(\theta_{3}-\theta_{1}\right)^{\tau}}\right]}
$$

Now multiplying both sides of equation (74) by $I$, the net generated power per unit volume is

* Saturation behavior in the pressure range of this study is represented by the homogeneous broadening limit since $\sqrt{1+I / I_{s}} \Delta \nu_{L} \geq$ $\Delta \nu_{\mathrm{D}} \cdot{ }^{32}$ This is because broadening actually increases as intensity increases (intensity broadening). 


$$
I \gamma=\frac{I \gamma_{0}}{1+\frac{I}{I_{s}}}=I_{s} \gamma_{0}\left(1-\frac{I s}{I+I_{s}}\right)
$$

and its profile is plotted in Figure 9 below.

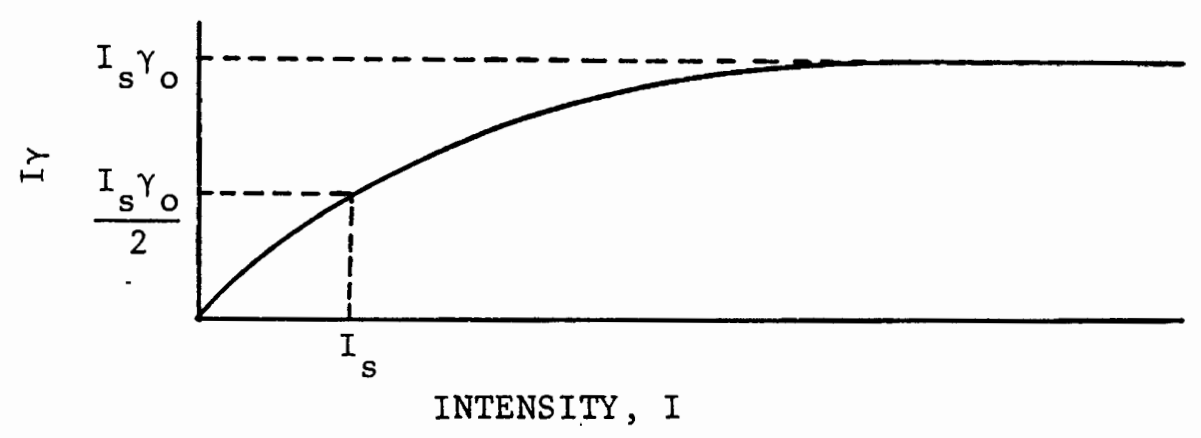

Figure 9. Net generated power per unit volume versus intensity.

As can be seen from Figure 9, the maximum available power per unit volume is $I_{s} \gamma_{o}$ (where $I \gg I_{s}$ ), the value of which is given by the expression below as obtained from equations (73) and (75).

$$
\frac{P_{\max }}{V_{m}}=I_{s} \gamma_{0}=\frac{\left(\frac{\xi_{3}}{\theta_{3}} \tau_{3}-\frac{3}{2} \frac{\xi_{1}}{\theta_{3}} \tau_{1}\right) R-\frac{\xi_{1}}{\theta_{1}} \bar{E}_{12}}{\frac{\xi_{3}}{\theta_{3}-\theta_{1}} \tau_{3}-\frac{\xi_{1}}{2\left(\theta_{3}-\theta_{1}\right)} \tau_{1}}
$$

\subsubsection{Cavity Losses and Output Coupling}

So far we have not considered cavity losses such as those due to scattering, absorption, diffraction (these are called residual losses), and useful output transmission. But in order to figure the actual output power, we have to determine those losses.

Scattering and absorption by the mirrors will generally be small and is usually less than a percent (mainly by absorption). Diffraction is dependent on many parameters such as cavity length $\ell$, radius of the mirrors, curvature of the mirrors, and the transverse mode configuration 
of the laser beam. For the cavity dimensions found necessary in this study the diffraction loss can be held to less than a percent (see Section 3.1.1).

Regarding the output loss, it should be noted that there is a trade-off between the two extremes; i.e. if output mirror loss is too large, internal cavity losses are too large for laser oscillation, and on the other hand if the mirror transmission is too small, almost no useful power is coupled out.

The fraction of the intensity lost per single pass, $\mathrm{L}$, is

$$
\mathrm{L}=\mathrm{L}_{i}+\mathrm{T}
$$

where

$\mathrm{L}_{i}:$ residual loss per single pass

$T$ : useful mirror transmission (average of both mirrors)

The optimum $T$ to maximize the power output is given by 34

$$
T_{\text {opt }}=-I_{i}+\sqrt{\gamma_{o l L_{i}}}
$$

\subsubsection{Threshold Gain and Output Power}

Once the oscillation starts, the gain is reduced by gain saturation and clamped at the threshold value regardless of the pumping. At this point the gain per pass is equal to the loss per pass, i.e.

$$
\gamma_{t} l=L
$$

This is valid for small losses, i.e. $\mathrm{L} \ll<1$.

From equation ( 80$)$ and (74) at threshold, the intensity I can be written as

$$
I=I_{s}\left(\frac{\gamma_{0}}{\gamma_{t}}-1\right)=I_{s}\left(\frac{\gamma_{0} \ell}{L}-1\right)
$$


The cavity power considering losses is consequently given by

$$
P_{e}=\left(I \gamma_{t}\right) V_{m}=I_{s} A_{m}\left(\gamma_{0} l-L\right)
$$

where $A_{m}=V_{m} / l$ is the cross-sectional area of the beam.

The fraction of the cavity power that is coupled out of the laser cavity as a useful output is $T / L$.

The power output is thus,

$$
\mathrm{P}_{\mathrm{o}}=\frac{\mathrm{T}}{\mathrm{L}} \mathrm{P}_{\mathrm{e}}
$$

Combining equations $(73),(75),(82)$, and $(83), \mathrm{P}_{\mathrm{o}}$ is finally written as

$$
\begin{aligned}
P_{0} & =\left\{\frac{k_{v}}{\left(\frac{G_{0}}{N}\right)\left(\theta_{3}-\theta_{1}\right)} \frac{1}{\left(\xi_{3} \tau_{3}-\frac{1}{2} \xi_{1} \tau_{1}\right)}\right\} \frac{V_{m}}{\ell} T \\
& \times\left\{\frac{\left(\frac{G_{0}}{N}\right) l}{\mathrm{kQ}_{\mathrm{V}} \theta_{3} L}\left[\left(\xi_{3} \tau_{3}-\frac{3}{2} \xi_{1} \tau_{1}\right) \frac{P_{I}}{V}-\frac{\theta_{3}}{\theta_{1}} \xi_{1} \bar{E}_{12}\right]-1\right\}
\end{aligned}
$$




\section{RESULTS AND DISCUSSION}

A computer program was written to facilitate the calculation of small signal gain $\gamma_{0}$, maximum available power $\mathrm{P}_{\max }$, cavity power $\mathrm{P}_{\mathrm{e}}$, output power $\mathrm{P}_{\mathrm{o}}$, optimum mirror transmission $\mathrm{T}_{\mathrm{opt}}$, efficiency $\left(n=P_{0} / P_{T}\right)$ and vibrational temperatures $T_{3}$ and $T_{1}$ of the upper and lower levels for any set of parameters for the $\mathrm{CO}_{2}$-He laser system. A $\mathrm{CO}_{2}$-He mixture was chosen as the laser medium; addition of helium effectively depopulates the lower level while populating the upper level only by a slight degree. Nitrogen was not used because it provides no advantage to a sun-pumped $\mathrm{CO}_{2}$ laser. The parameters that were varied included the gas temperature $T$, the total gas pressure $p$, the partial pressure of carbon dioxide $\mathrm{p}_{c}$, the beam radius $r_{m}$, the radius of the tube $r$, the length of the tube $l$, the absorption path length of the sunlight $l_{a}$, the residual loss per pass $L_{i}$, and the area of the solar energy collector $A_{s}$. Total pressure was varied in the range of $\mathrm{p}=0.01-0.05 \mathrm{~atm}$ where acceptable gain and output power were found to exist. Gas temperatures of $200^{\circ} \mathrm{K}$ and $300^{\circ} \mathrm{K}$ were taken since at lower temperatures (about $170^{\circ} \mathrm{K}$ ) carbon dioxide solidifies, and at temperatures above $300^{\circ} \mathrm{K}$ the gain was found to be too low for laser oscillation because of thermal population of the lower level.

Computed results are given first for a specific system model and then the effects on the laser performance of varying selected parameters are examined. The proposed system model is described in the following section. 


\subsection{PROPOSED LASER SYSTEM MODEL}

\subsubsection{Description of the System}

End pumping was chosen because it provides the necessary long sunlight absorption path length in comparison to side pumping. Side pumping is of course possible as another alternative approach that could be studied. Although the length of the tube should be long to allow enough absorption, it cannot be too long because of practical size limitations and a higher diffraction loss. A tube of $1 \mathrm{~m}$ length was arbitrarily chosen with a $2 \mathrm{~m}$ absorption path length for the sunlight (i.e. one round-trip of the incident sunlight in the tube is assumed).

A collector size of $10 \mathrm{~m}^{2}$ was also arbitrarily chosen as the largest reasonable collector size physically and economically practical. The minimum possible spot size concentrated from a $10 \mathrm{~m}^{2}$ collector is limited to a $1.66 \mathrm{~cm}$ diameter area by the Abbe sine condition; therefore, the radius of the tube was determined to be $0.85 \mathrm{~mm}$.

The radius of the beam should be large so that as many of the excited molecules as possible participate in lasing action. This is especially important for a sun-pumped $\mathrm{CO}_{2}$ laser since the pump light is limited by collector size and should not be wasted. On the other hand, beam size for a given tube radius is limited by diffraction; the diffraction loss for a single mode beam is $1 \%$ for $r_{m}=\frac{2}{3} r$. and even larger for a multimode beam. ${ }^{36}$ The beam radius is therefore taken to be $5 \mathrm{~mm}$ in the initial case. 
The parameters for the laser tube and the collector area were thus selected as follows:

Area of the sun collector, $A_{s}=10 \mathrm{~m}^{2}$

Residual loss per pass, $\mathrm{L}_{i}=1 \%$

Beam radius, $r_{m}=0.5 \mathrm{~cm}$

Radius of the tube, $r=0.85 \mathrm{~cm}$

Length of the tube, $\ell=1 \mathrm{~m}$

Absorption path length of the sunlight, $l_{a}=2 \mathrm{~m}$

\subsubsection{Computed Results for Proposed Laser}

Computed results for small signal gain and output power are presented here às a function of the gas temperature and the total and partial pressures. The gain and power generally decrease as the gas temperature goes up because of the increase of the lower level population which is almost in equilibrium with the gas temperature. Thus, for the range of gas temperatures considered, the lowest possible temperature is optimum for this system.

3.1.2.1 Small signal gain: The variation of the gain with $\mathrm{CO}_{2}$ partial pressure. $P_{C}$ is plotted in Figure 10 for $200^{\circ} \mathrm{K}$ with total pressure as a parameter. A total pressure of greater than 0.05 atm yields too low a gain and is thus not considered further. Gain is a function of many parameters such as ' 1 inewidth, $\mathrm{CO}_{2}$ concentration, pumping power, and upper and lower level lifetimes. Among these parameters, pumping power and upper level lifetime have the dominant effects on gain at $200^{\circ} \mathrm{K}$, and these vary with the $\mathrm{CO}_{2}$ and total pressures. 


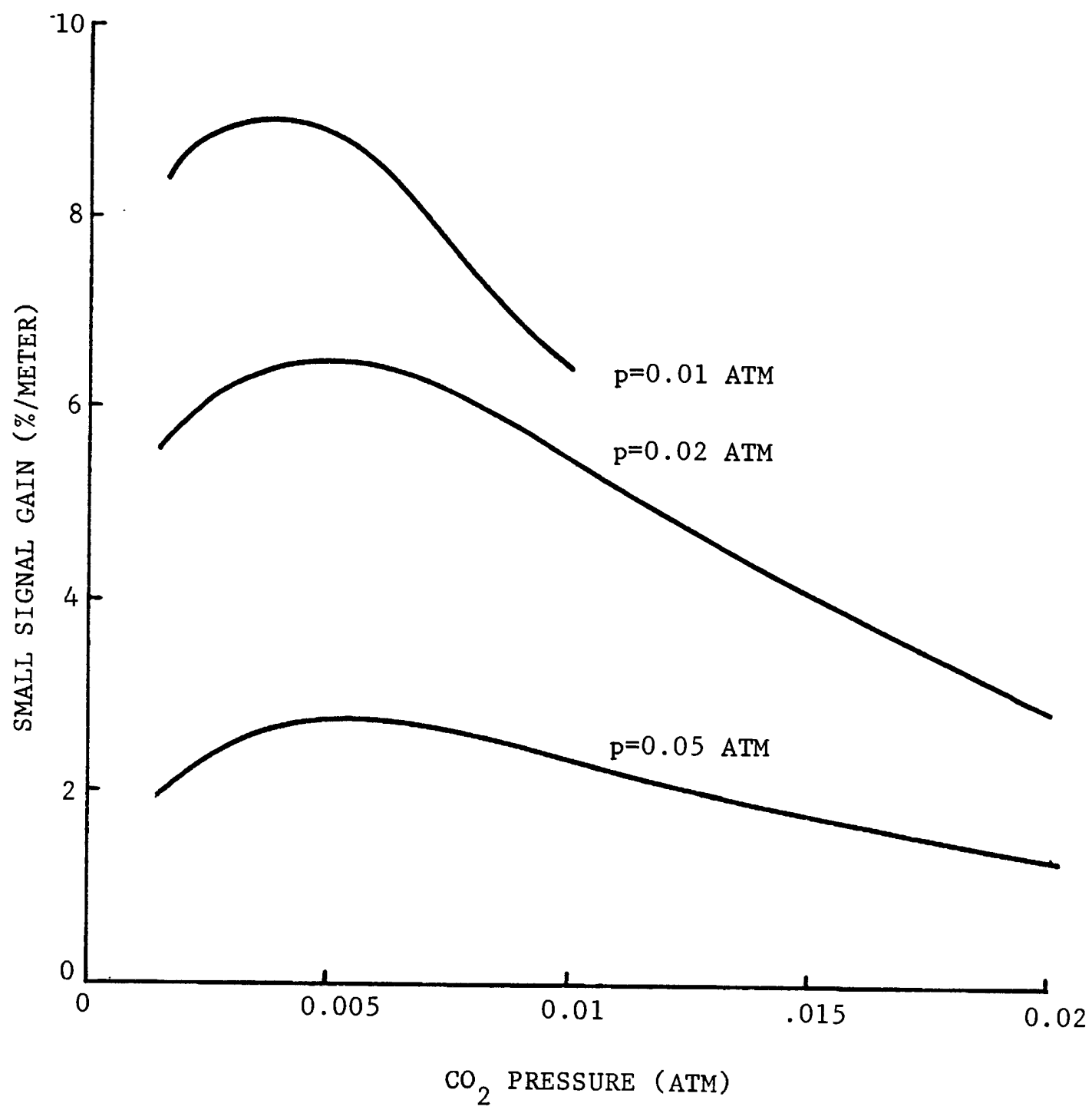

Figure 10. Variation of small signal gain with total and partial pressures. 
As the $\mathrm{CO}_{2}$ and total pressures increase, pumping power increases, but the upper level lifetime decreases. The maximum gain, then, occurs when the product of pumping power and upper level lifetime is a maximum. Because pumping is relatively weak such that the effect of the relaxation of the upper level predominates, maximum gain occurs at low partial and total pressures. At these low pressures thermal population of the lower level (100) is almost negligible compared with that of the pumped population of the upper level (001). Although the maximum gain is given at $\mathrm{p}=0.01 \mathrm{~atm}$ and $\mathrm{p}_{\mathrm{c}}=0.005$ atm, maximum output power is achieved at higher pressures (with high enough gain) as will be seen in the next section.

At $300^{\circ} \mathrm{K}$ thermalization of the lower level reduces the gain considerably to a value which is generally too low to be able to enable lasing action. A maximum gain of only $2.5 \% /$ meter was obtained in the $300^{\circ} \mathrm{K}$ case. Hence, the gas temperature was held at $200^{\circ} \mathrm{K}$.

3.1.2.2 Output Power: Shown in Figure 11 is the plot of output power at $200^{\circ} \mathrm{K}$. Output power is the power which comes out of the laser cavity through the partially transmitting mirror whose optimum transmission is calculated from equation (79). As one can see from expressions (82) and (83), output power varies with saturation intensity, small signal gain and residual losses as well as beam volume. Saturation intensity is a function of linewidth, pumping power, and upper and lower level lifetimes. 


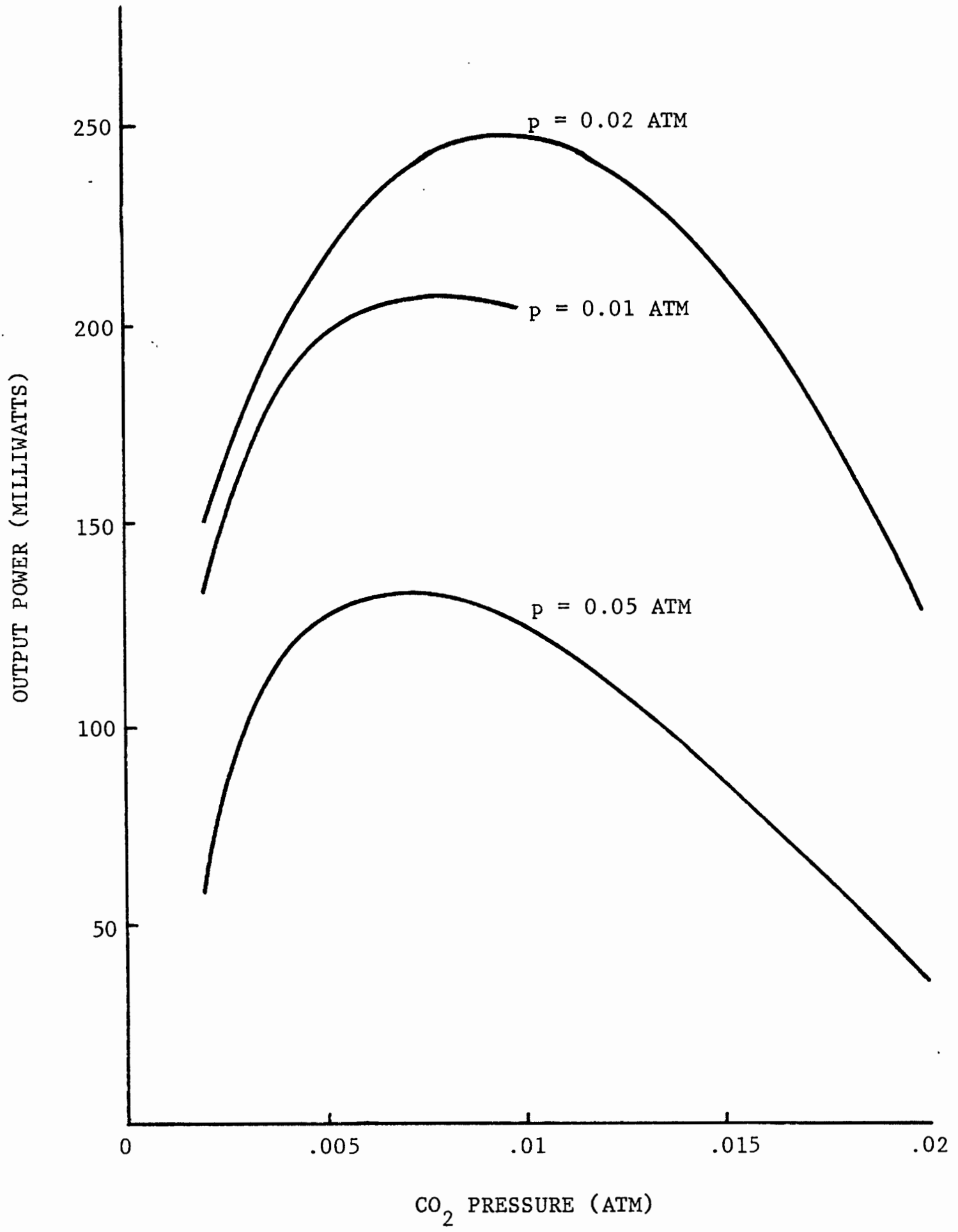

Figure 11. Variation of output power with total and partial pressures. 
At $200^{\circ} \mathrm{K}$ a maximum output power of about 250 milliwatts was obtained at $\mathrm{p}=0.02$ atm and $\mathrm{P}_{\mathrm{c}}=0.01$ atm with $1.3 \%$ mirror transmission. These pressures correspond to a rather low, non-optimum gain of $5.4 \% /$ meter, which would, however, still be sufficient to sustain laser oscillation.

3.1.2.3 Overall Performance: Enough gain and high output power are the requirements for good laser performance. Since the sun-pumped $\mathrm{CO}_{2}$ laser is found to be a modest power, low gain system, it must operate at conditions where the gain is sufficient and the power is highest. The optimum performance of the assumed laser system is summarized as follows:

$\begin{array}{ll}\text { Temperature: } & 200{ }^{\circ} \mathrm{K} \\ \text { Total pressure: } & 0.02 \mathrm{~atm} \\ \mathrm{CO}_{2} \text { pressure: } & 0.01 \mathrm{~atm} \\ \text { Small signal gain: } & 5.4 \% / \text { meter or } 5.4 \% / \text { pass } \\ \text { Output power: } & 250 \text { milliwatts } \\ \text { Efficiency: } & 4.1 \% \\ \text { Optimum mirror transmission: } 1.3 \%\end{array}$

3:2 EFFECTS OF PARAMETER VARIATION ON THE SMALL SIGNAL GAIN AND THE OUTPUT POWER

For the selected temperature of $200^{\circ} \mathrm{K}$, various parameters that were preselected to initially determine the gain and the output power 
are now varied to note the sensitivity of the performance to variations of the individual variables.

Each of the Figures 12-15 shows the variation of the gain and the output power due to the change of one parameter selected from the proposed system model; the six parameters changed are residual loss $L_{i}$, collector area $A_{s}$, radii of the beam $r_{m}$ and the tube $r$, and the lengths of the absorption path $\ell_{a}$ and the tube $\ell$.

The effect of varying residual losses is noted in Figure 12 .

The losses are taken to increase from $1 \%$ to $2 \%$ and then to $3 \%$. The gain remains the same since it is independent of losses, but the output power decreases to $1 / 2$ for $L_{i}=2 \%$, and to $1 / 3$ for $L_{i}=3 \%$. Achieving losses of less than $1 \%$ would be difficult, but would result in a large power increase. Thus, the magnitude of residual loss is an important parameter.

The collector size directly affects the output power and gain as shown in Figure 13. As collector size varies, tube radius and beam radius are also adjusted accordingly. The tube radius was matched with the minimum spot size (by the Abbe Sine condition) concentrated from each collector area. The beam radius was kept slightly smaller than $2 / 3$ of the tube radius for minimum diffraction loss. Since the pumping power density stays the same with varying collector size and, hence, tube radius (i.e. the maximum intensity of concentrated sunlight is limited by the Abbe Sine condition), the gain stays essentially constant. On the other hand, output power increases proportionally with collector size and, hence, with beam volume. For example, by reducing collector area by one-half (from $10 \mathrm{~m}^{2}$ to $5 \mathrm{~m}^{2}$ ) so that the beam volume 


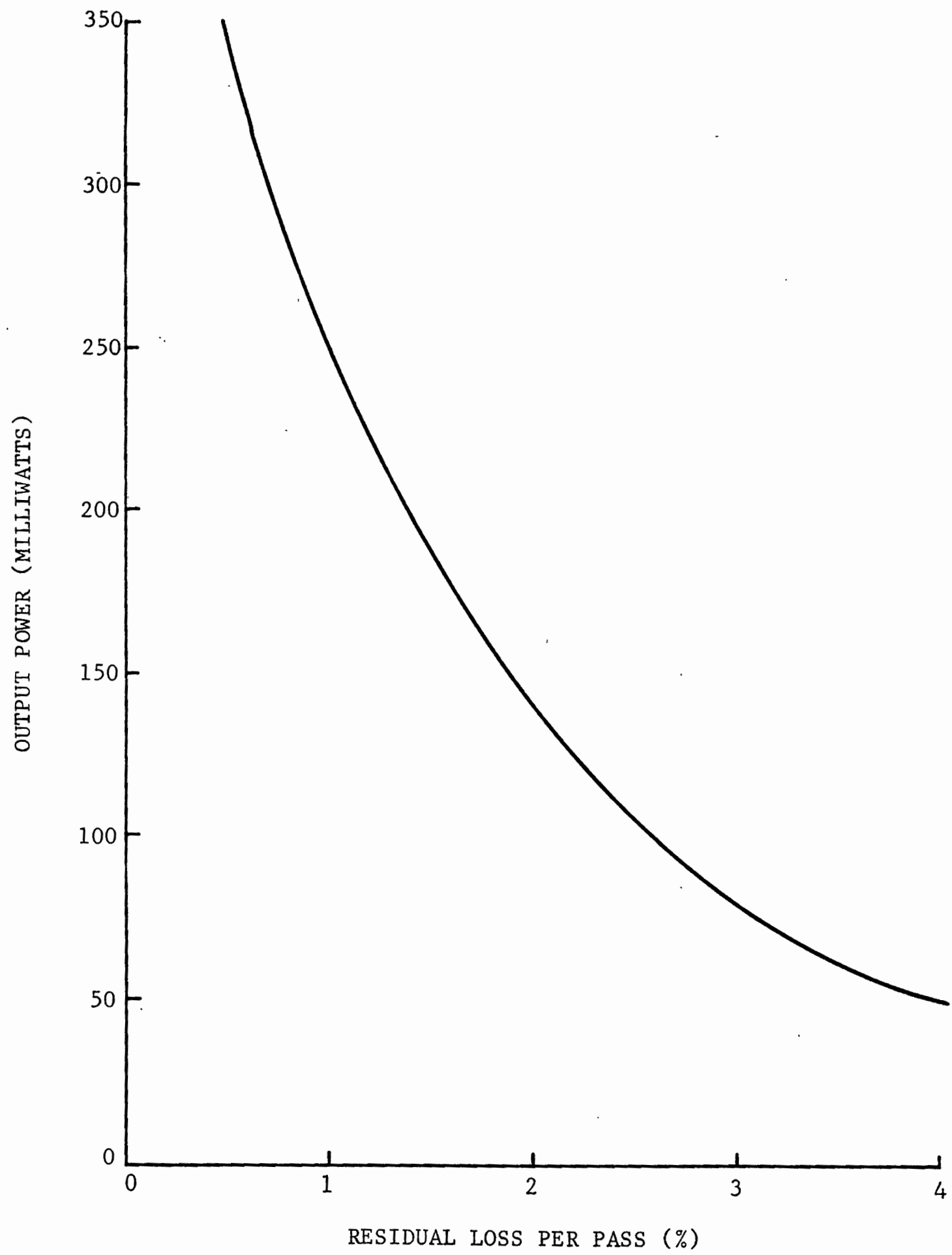

$\frac{\text { Figure 12. }}{\text { at } 200 \mathrm{~K} \text {. }}$ Output power versus residual loss per pass 


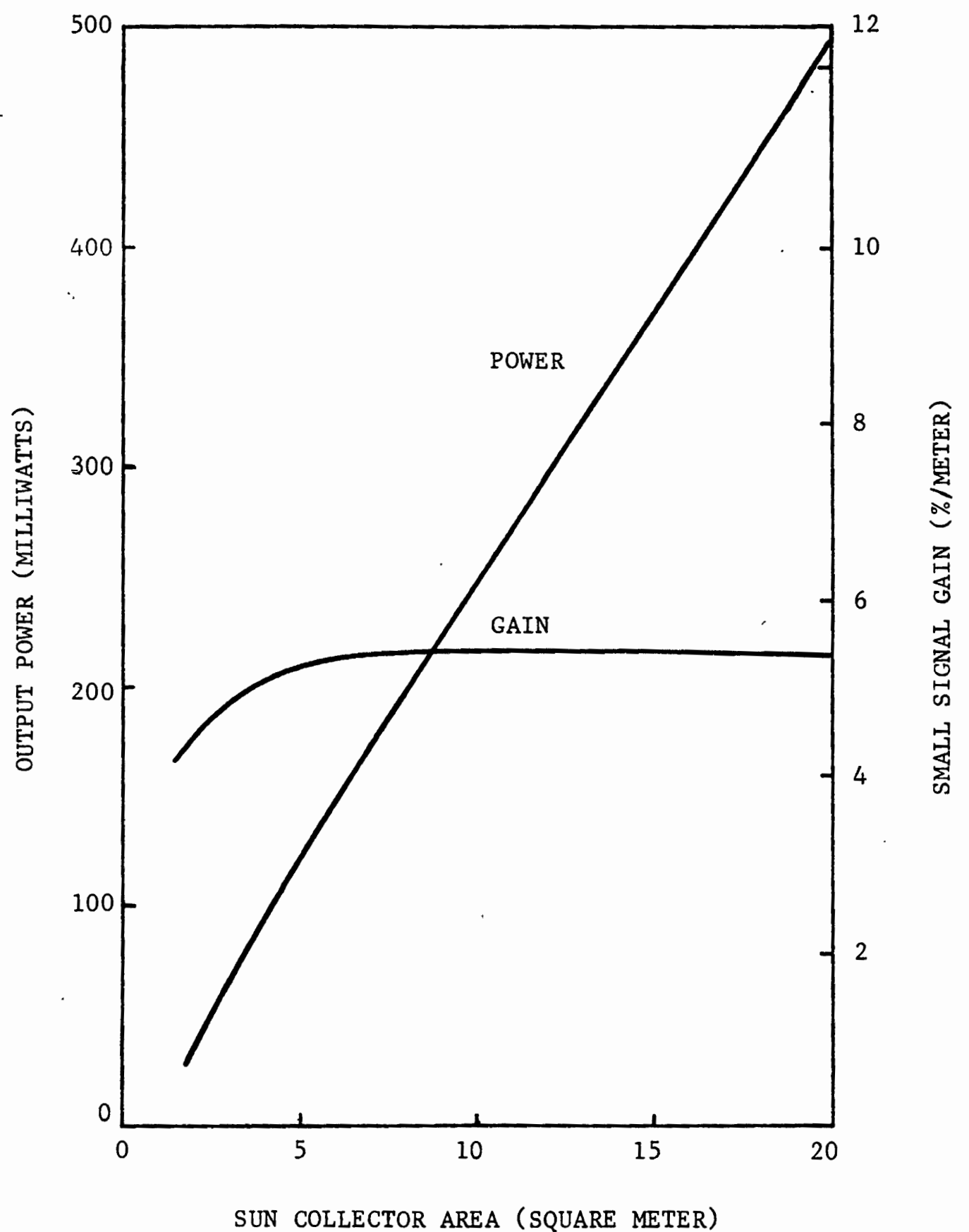

Figure 13. Output power and small signal gain versus sun collector area at $200 \% \mathrm{~K}$. 
(or beam spot size) is decreased by one-half, the output power goes down by one-half, while the pumping power density and, therefore, the gain stays constant. Although power increases with collector area, considering physical constraints, a collector much larger than $10 \mathrm{~m}^{2}$ would not be very practical. Besides, a larger beam size is also required for a larger collector. That would also be hard to achieve. For the constant collector $\left(10 \mathrm{~m}^{2}\right)$ and the tube size $(0.85 \mathrm{~cm}$ radius), only the beam size is varied in Figure 14. A smaller beam causes the pumping power to be wasted outside the beam volume, reducing the output power drastically. A beam larger than about $0.5 \mathrm{~cm}$, on the other hand, will result in too high a diffraction loss which would lower the output. The results of Figure 14 do not include the effect of such increased losses.

As shown in Figure 15, both the gain and the output power are fairly strong functions of the absorption path length of sunlight. This result comes from the fact that in this low pressure range $(p=0.02 \mathrm{~atm})$ an absorption path length longer than $2 \mathrm{~m}$ would be necessary to completely absorb the incident sunlight. The output power approaches a maximum for an absorption length of about $8 \mathrm{~m}$. An absorption length longer than $2 \mathrm{~m}$ would appear from Figure 15 to result in increased output power. However, the longer tube results in increased diffraction loss or a reduced mode volume that does not fully utilize the pump light. In fact, the output power is a maximum with about $2 \mathrm{~m}$ absorption length. It should be noted that gain per pass is plotted in Figure 15 rather than gain per meter. This is because comparison of gains should be made for single pass gain, not 


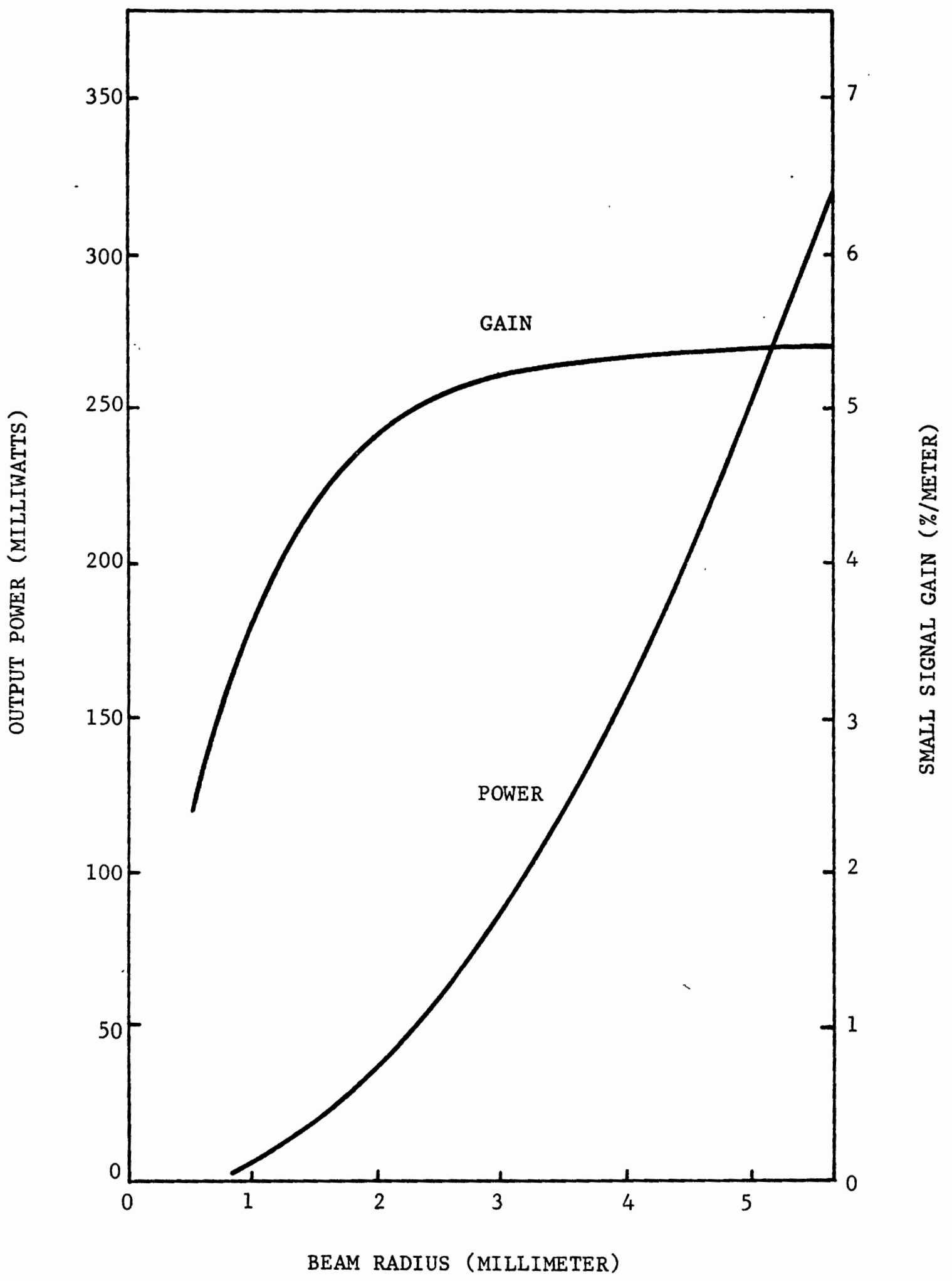

Figure 14. Output power and small signal gain versus beam radius. 


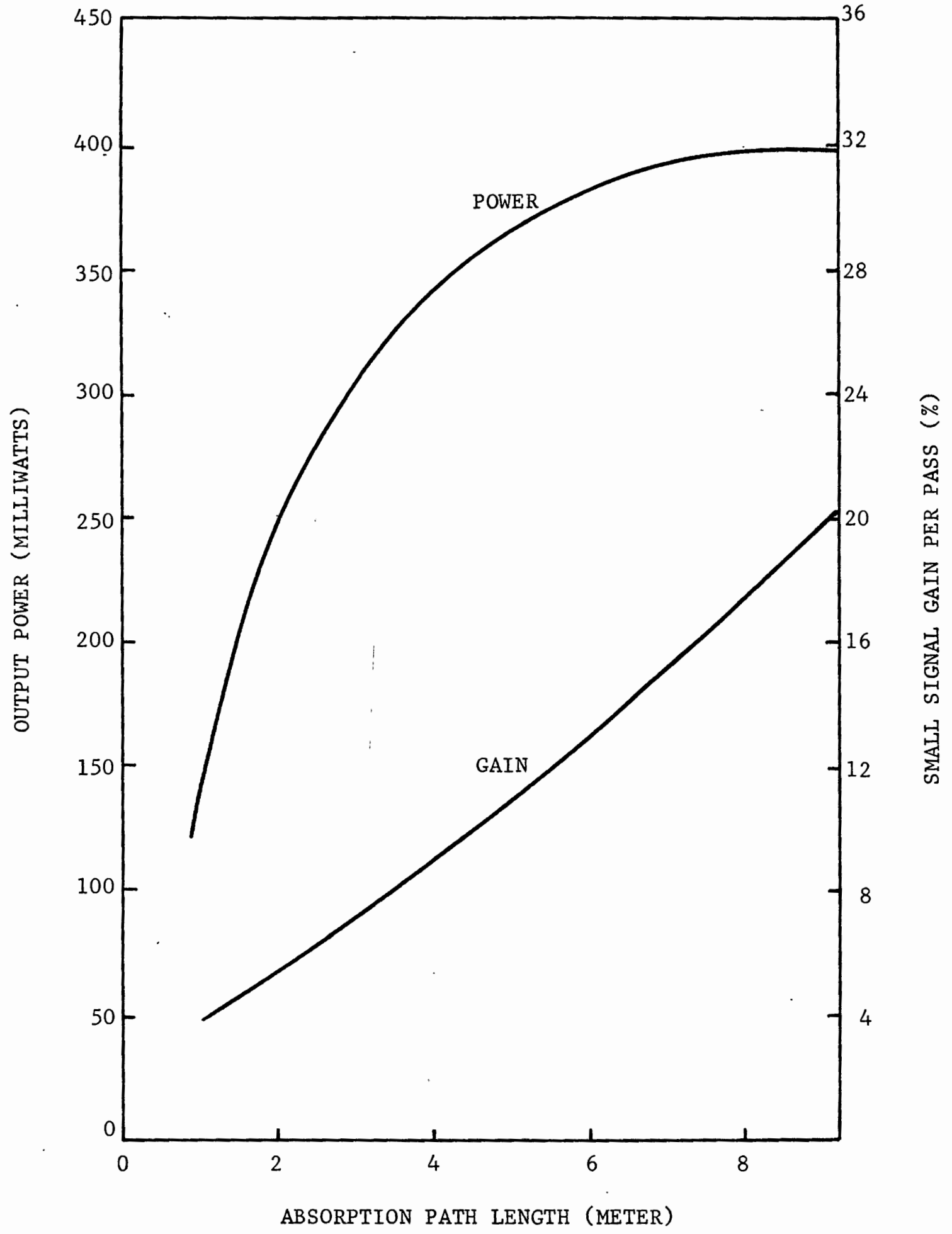

Figure 15. Output power and small signal gain per pass versus absorption path length at $200^{\circ} \mathrm{K}$. 
gain per unit length for different tube lengths.

In summary, when the various parameters are varied as above, the output power varies more than the gain. The initially proposed laser system in fact has the optimum power and reasonable gain. However, it is not likely that more than 500 milliwatts could be obtained from the sun-pumped $\mathrm{CO}_{2}$ laser design presented here.

\subsection{PRACTICAI DESIGN CONSIDERATIONS}

In the foregoing discussions it has been assumed that the sunlight could appropriately be collected, concentrated, and then absorbed in the $\mathrm{CO}_{2}$ gas mixtures. A schematic diagram of the end-pumping method assumed is shown in Figure 16 below.

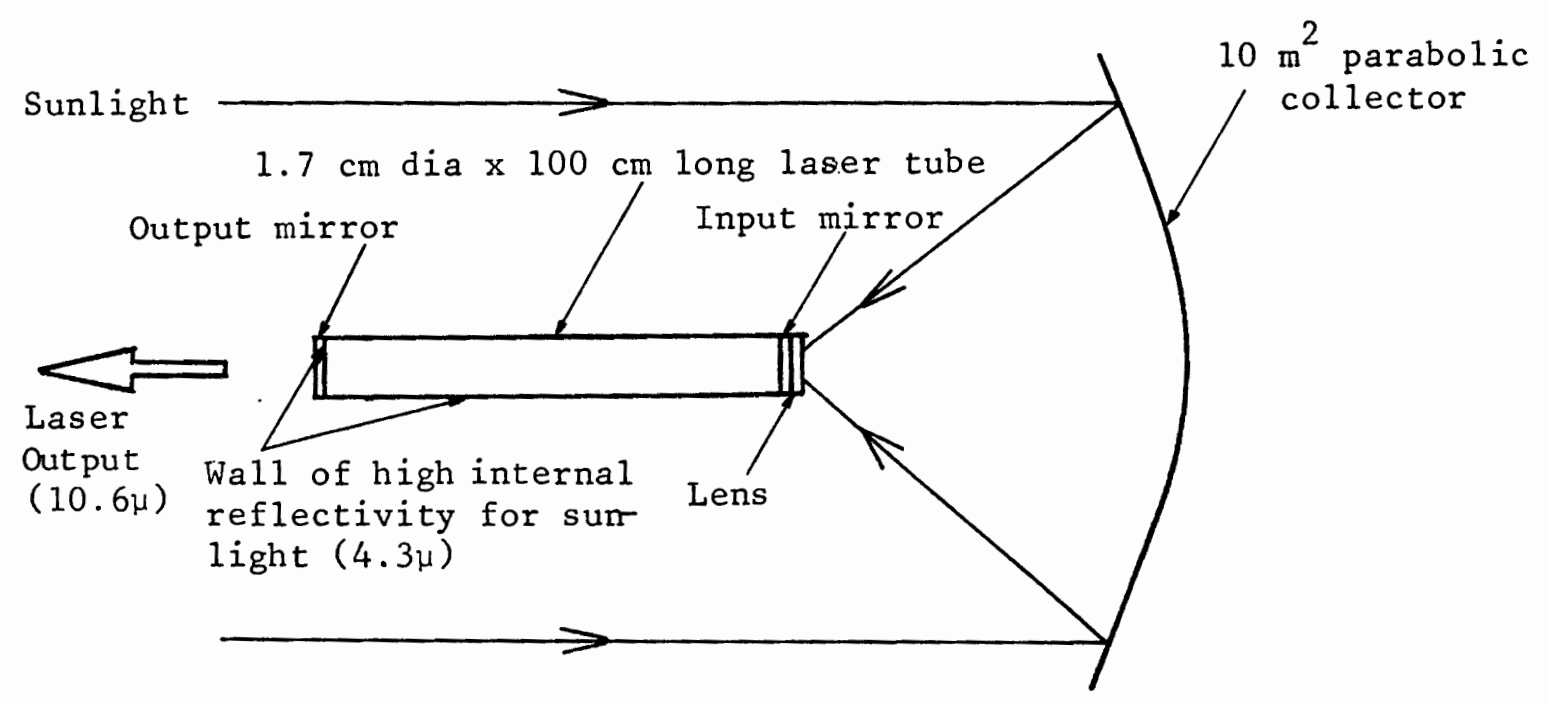

Figure 16 . Schematic diagram of a sun-pumped $\mathrm{CO}_{2}$ laser with end-pumping. 
In this scheme sunlight collected by a large parabolic collector is focused into a lens that produces essentially parallel pump light which is transmitted into the laser tube. Other possible means of collecting and leading sunlight into the laser tube could be developed and used. For example, side-pumping might be another alternative method if long sunlight absorption path lengths could be achieved.

The laser output mirror and sunlight input mirror must be appropriately coated so that they transmit light selectively according to wavelength; the output mirror is partially transmitting for 10.6 micron laser light and reflective for 4.3 micron pumping light. The input mirror is transparent in the 4.3 micron region and reflective at 10.6 microns.

The other main practical consideration for a sun-pumped spacequalified $\mathrm{CO}_{2}$ laser is cooling the laser medium. Conductive cooling of the laser tube and use of heat pipes to remove the heat to a radiative cooler is considered to be the preferred design technique for a space qualified laser because of its low weight and high reliability. ${ }^{1,5}$ 


\section{CONCLUSIONS}

The possibility of directly sun-pumping a $\mathrm{CW} \mathrm{CO}_{2}$ laser in space has been analyzed for the first time, and the gas kinetic analysis indicates that end-pumping such a laser is feasible. However, since this laser system is pump deficient, it is essential to keep the residual losses such as diffraction, absorption, and scattering to a minimum, and also to concentrate the sunlight down to an almost theoretical minimum spot size in order to obtain the highest pumping power density. The gas temperature must also be held low (but higher than about $170^{\circ} \mathrm{K}$ ) to achieve the highest possible gain and output power.

Since pumping must take place at low gas pressures to achieve sufficient gain, the power output is modest. In principle the output can be increased by utilizing a larger sunlight collector area, but practical difficulties with a larger collector and the necessarily larger laser beam diameter limit this approach. Long absorption paths could also be used to achieve higher powers, but the amount of improvement is again practically limited. It is possible that addition of other gases to the $\mathrm{CO}_{2}$-He mixture could increase the output power by increasing the absorption of sunlight without adversely affecting the upper level lifetime. This possibility for increasing the output should be further examined. Nonetheless, at this time it would appear that the maximum achievable continuous power obtainable with the laser design presented here is about 500 
milliwatts. Therefore, it does not look like high powers can be achieved using this approach. In addition, it should be noted that this particular type of $\mathrm{CO}_{2}$ laser would not appear to be capable of operation at pressures above atmospheric where continuous tunability can be achieved.

It should be noted that output powers of greater than one watt have already been achieved with a sun-pumped Nd:YAG laser. However, if it is desirable or necessary to utilize a modest power carbon dioxide laser or if its output wavelength is preferred, then this study shows that such a laser is feasible. To examine its performance in more detail, laboratory measurements would have to be made to determine how much sunlight can actually be absorbed and how much gain can be achieved under the conditions predicted to give optimum performance. 


\section{REFERENCES}

1. J.D. Foster and R.F. Kirk, "Space Qualified Nd:YAG Laser'," Final Technical Report, Contract No. NAS102-2160, June 1970.

2. C.G. Young, "A Sun Pumped CW One-Watt Laser," Applied Optics, Vo1. 5, No. 6, p. 993, June 1966.

3. G.R. Simpson, "Continous Sun-Pumped Room Temperature Glass Laser Operation," Applied Optics, Vol. 3, No. 6, p. 783, June 1964.

4. D.F. Nelson and N.S. Boyle, "A. Continuously Operating Ruby Optical Maser," Applied Optics, Vol. 1, No. 2, p. 181, March 1962.

5. L. Huff, "Sun Pumped Laser," Final Technical Report, Contract No. AFAL-TR-71-315, September 1971.

6. D.C. Forster, F.E. Goodwin, and W.B. Bridges, "Wide-Band Laser Communications in Space," IEEE Journal of Quantum Electronics, Vo1. QE-8, No. 2, p. 263, February 1972.

7. P.A. Bokhan and G.I. Talarkina, "On The Possibility of Optical Pumping of Gases by Their Own Radiation," Optics and Spectroscopy, Vo1. 25, No. 4, p. 298, October 1968.

8. P.A. Bokhan, "On Optical Pumping of a Molecular Laser by Blackbody Radiation," Optics and Spectroscopy, Vol. 26, No. 5, p. 423, May 1969.

9. P.A. Bokhan, "Experiment on Optical Pumping of a Carbon Dioxide Molecular Laser," Optics and Spectroscopy, Vo1. 32, No. 4, p. 435, April 1972.

10. I. Wieder, "Flame Pumping and Infrared Maser Action in $\mathrm{CO}_{2}$," Physics Letters, Vol. 24A, No. 13, p. 759, June 1967.

11. O. Yesil and W.H. Christiansen, "Solar Pumped Continuous Wave Carbon Dioxide Laser," Progress in Astronautics and Aeronautics, Vo1. 61, p. 357, January 1978.

12. H. Shirahata, S. Kawada and T. Sujioka, "Atmospheric Pressure CW $\mathrm{CO}_{2}$ Laser Pumped by Blackbody Radiation," 5 th Conference on Chemical and Molecular Lasers, St. Louis, Mo., April 1977. 
13. T.Y. Chang and O.R. Wood, II, "Optically Pumped AtmosphericPressure $\mathrm{CO}_{2}$ Laser," Applied Physics Letters, Vol. 21, No. I, p. 19, July 1972 .

14. T.Y. Chang and O.R. Wood, "Optically Pumped 33-atm $\mathrm{CO}_{2}$ Laser," Applied Physics Letters, Vol. 23, No. 7, p. 370, October 1973.

15. N. Robinson, Solar Radiation, Elsevier Publishing Company, New York, 1966, p. 2 .

16. V.R. Stull, P.J. Wyatt, and G.N. Plass, "The Infrared Transmittance of Carbon Dioxide," Applied Optics, Vol. 3, No. 2, p. 243, February 1964.

17. V.R. Stu11, P.J. Wyatt, and G.N. Plass, "The Infrared Absorption of Carbon Dioxide, Infrared Transmission Studies," Vol. III, Report SSD-TDR-62-127, Space Systems Division, Air Force Systems Command, Los Angeles, California, January 1963 .

18. W.G. Vincenti and C.H. Kruger, Jr., Introduction to Physical Gas Dynamics, John Wiley \& Sons, Inc., New York, 1965, p. 133, p. 119, and p. 206.

19. V.P. Tychinskii, "Powerful Gas Lasers," Soviet Physics Us pekhi, Vol. 10, No. 2, p. 131, September 1967.

20. H. Statz, C.L. Tang, and G.F. Koster, "Transition Probabilities Between Laser States in Carbon Dioxide," Journal of Applied Physics, Vo1. 37, No. 11, p. 4278, October 1966.

21. D.R. Whitehouse, "High Power Gas Laser Research," Fina1 Technical Report, Contract DA01-021-AMC-12427(Z), p. 11, May 1967.

22. H. Granek, C. Freed, and H.A. Haus, "Experiment on Cross Relaxation in $\mathrm{CO}_{2}$," IEEE Journal of Quantum Electronics, Vo1. QE-8, No. 4, p. 404, April 1972.

23. H. Granek, "The Observation of Diffusion as an Effective Vibrational Relaxation Rate in $\mathrm{CO}_{2}$," IEEE Journal of Quantum Electronics, Vol. QE-10, No. 3, p. 320, March 1974.

24. J.T. Yardley and C.B. Moore, "Intramolecular Vibration-toVibration Energy Transfer in Carbon Dioxide," The Journal of Chemical Physics, Vo1. 46, No. 11, p. 4491, June 1967.

25. A.K. Levine and A.J. DeMaria, Lasers, Marcel Dekker, Inc., New York, 1971, p. 150. 
26. C.B. Moore, R.T. Wood, Bei-Lok Hu, and J.T. Yardley, "Vibrational Energy Transfer in $\mathrm{CO}_{2}$ Lasers," The Journal of Chemical Physics, Vo1. 46, No. 11, 2 . 4222, June 1967.

27. R.L. Taylor and S. Bitterman, "Survey of Vibrational Relaxation Data for Processes Important in the $\mathrm{CO}_{2}-\mathrm{N}_{2}$ Laser Systems," Reviews of Modern Physics, Vol. 4I, No. 1, p. 26, January 1969.

28. R.L. Taylor and S. Bitterman, "Survey of Vibrational Relaxation Data for Processes Important in the $\mathrm{CO}_{2}-\mathrm{N}_{2}$ Laser System," Research Report 282, Contract F33(615)-68-C-1030, October 1967.

29. W.A. Rosser, Jr., A.D. Wood, and E.T. Gerry, "Deactivation of Vibrationally Excited Carbon Dioxide ( $v_{3}$ ) by Collisions with Carbon Dioxide or with Nitrogen," The Journal of Chemical Physics, Vo1. 50, No. 11, p. 4996, June 1969.

30. A.L. Hoffman and G.C. Vlases, "A Simplified Model for Predicting Gain, Saturation, and Pulse Length for Gas Dynamic Lasers," IEEE Journal of Quantum Electronics, Vol. QE-8, No. 2, p. 46, February 1972.

31. R.I. Abrams, "Broadening Coefficients for the $P(20)$ Laser Transition," Applied Physics Letters, Vol. 25, No. 10, p. 609, November 1974.

32. W.B. Lacina, "Kinetic Model and Theoretical Calculations For Steady State Analysis of Electrically Excited Co Laser Amplifier Systems," Final Report: Part II, Contract No. N00014-71-C-0037, p. 21, p. 35, August 1971.

33. D.J. Eckstrom, "Vibrational-Relaxation Measurements in Schock-Heated Carbon Dioxide by Tuned-Laser Absorptivity," SUIPR Report No. 414, SUDAAR No. 420, p. 106, Institute For Plasma Research, Stanford University, Stanford, California, March 1971.

34. A. Yariv, Introduction to Optical Electronics, Holt, Rinehart, and Winston, Inc., U.S.A., 1971, p. 111.

35. F.A. Jenkins and H.E. White, Fundamentals of Optics, McGrawHi11 Book Company, Inc., New York, 1957, p. 154.

36. A.E. Siegman, An Introduction to Lasers and Masers, McGrawHi11 Book Company, Inc., New York, 1971, p. 335. 